\title{
Activation of Toll-like receptor 5 in microglia modulates their function and triggers neuronal injury
}

\author{
Masataka Ifuku ${ }^{1,7 \dagger}$, Lukas Hinkelmann ${ }^{2 \dagger}$, Leonard D. Kuhrt ${ }^{1,3}$, Ibrahim E. Efe ${ }^{1,3}$, Victor Kumbol ${ }^{2}$, \\ Alice Buonfiglioli ${ }^{1,2}$, Christina Krüger ${ }^{2}$, Philipp Jordan ${ }^{1}$, Marcus Fulde ${ }^{4}$, Mami Noda ${ }^{5}$, Helmut Kettenmann ${ }^{1 \dagger}$ \\ and Seija Lehnardt ${ }^{2,6^{*}+}$ (i)
}

\begin{abstract}
Microglia are the primary immune-competent cells of the central nervous system (CNS) and sense both pathogenand host-derived factors through several receptor systems including the Toll-like receptor (TLR) family. Although TLR5 has previously been implicated in different CNS disorders including neurodegenerative diseases, its mode of action in the brain remained largely unexplored. We sought to determine the expression and functional consequences of TLR5 activation in the CNS. Quantitative real-time PCR and immunocytochemical analysis revealed that microglia is the major CNS cell type that constitutively expresses TLR5. Using T/r $5^{-1-}$ mice and inhibitory TLR5 antibody we found that activation of TLR5 in microglial cells by its agonist flagellin, a principal protein component of bacterial flagella, triggers their release of distinct inflammatory molecules, regulates chemotaxis, and increases their phagocytic activity. Furthermore, while TLR5 activation does not affect tumor growth in an ex vivo GL261 glioma mouse model, it triggers microglial accumulation and neuronal apoptosis in the cerebral cortex in vivo. TLR5-mediated microglial function involves the PI3K/Akt/mammalian target of rapamycin complex 1 (mTORC1) pathway, as specific inhibitors of this signaling pathway abolish microglial activation. Taken together, our findings establish TLR5 as a modulator of microglial function and indicate its contribution to inflammatory and injurious processes in the CNS.
\end{abstract}

Keywords: Toll-like receptor 5, Microglia, PI3K/Akt/mTORC1 signaling, Cytokines, Phagocytosis, Chemotaxis, Neuronal apoptosis

\section{Background}

Toll-like receptors (TLRs) are pattern recognition receptors that are activated by both pathogen- and hostderived, potentially damage-associated, molecular patterns [61]. Engagement of these membrane receptors in the brain can result in various outcomes, such as

\footnotetext{
*Correspondence: seija.lehnardt@charite.de

${ }^{\dagger}$ Masataka Ifuku, Lukas Hinkelmann, Helmut Kettenmann, Seija Lehnardt contributed equally.

${ }^{2}$ Institute of Cell Biology and Neurobiology, Charité - Universitätsmedizin Berlin, corporate member of Freie Universität Berlin, HumboldtUniversität zuBerlin, and Berlin Institute of Health, Berlin, Germany Full list of author information is available at the end of the article
}

chronic inflammation, neuronal injury, either in a cellautonomous or inflammation-associated fashion, or in regenerative processes $[36,40,57]$. Among the 13 members of the TLR family in mouse and human characterized to date, TLR5 is the only protein-binding TLR that is conserved in vertebrates from fish to mammals, and specifically recognizes flagellin, a fibrillar protein derived from bacteria [22, 31, 59]. Examples of flagellated bacteria are Escherichia coli and Salmonella Typhi, which both can enter the central nervous system (CNS), thereby causing meningitis and/or brain abscesses [1, 9, 19, 34]. Furthermore, recent studies identified TLR5 as being involved in different CNS disorders lacking a primarily original author(s) and the source, provide a link to the Creative Commons licence, and indicate if changes were made. The images or other third party material in this article are included in the article's Creative Commons licence, unless indicated otherwise in a credit line to the material. If material is not included in the article's Creative Commons licence and your intended use is not permitted by statutory regulation or exceeds the permitted use, you will need to obtain permission directly from the copyright holder. To view a copy of this licence, visit http://creativecommons.org/licenses/by/4.0/. The Creative Commons Public Domain Dedication waiver (http://creativeco mmons.org/publicdomain/zero/1.0/) applies to the data made available in this article, unless otherwise stated in a credit line to the data. 
pathogen-associated cause, including Alzheimer's disease (AD), neuropathic pain, and cerebral ischemia [7, 24, 33, 64]. In peripheral immune cells such as dendritic cells and monocytes, and epithelial cells, flagellin-induced activation of TLR5 triggers PI3K signaling resulting in NF- $\mathrm{kB}$ activation, thereby modulating the innate immune response [13, 15, 47, 48, 56]. However, the TLR5-induced signaling cascade in the CNS is unresolved.

Microglia are the brain's primary sensor for pathologic events and express all TLRs identified so far, including TLR5 [52]. Activation of distinct TLRs can affect diverse microglial functions including migration (via TLR7, [29]) and cytokine release (via TLR2, TLR4, TLR7, [5, 38, 40]). In the present study, we sought to systematically analyze the expression and function of TLR5 in the CNS. In particular, we focused on the molecular mechanisms and signaling pathway promoting microglial chemotaxis, phagocytosis, cytokine production, and interaction with glioma cells as a consequence of TLR 5 activation in these cells. Furthermore, we analyzed whether microglial TLR5 activation may lead to neuronal injury.

\section{Methods \\ Reagents}

Purified recombinant flagellin from Salmonella Typhimurium (FLA-ST Ultrapure) and loxoribine were purchased from InvivoGen (San Diego, CA, USA). Lipopolysaccharide (LPS) was purchased from Enzo Life Sciences (Lörrach, Germany). LY294002 was obtained from Cell Signaling Technology (Danvers, MA, USA), while wortmannin and rapamycin were purchased from Sigma-Aldrich (St. Louis, MO, USA). Akt inhibitor IV was obtained from Calbiochem (San Diego, CA, USA). LY294002, Wortmannin, and rapamycin were solved in dimethyl sulfoxide (DMSO; Sigma-Aldrich, St. Louis, MO, USA). In all experiments using the inhibitors, DMSO-containing DMEM medium complete (see below; DMSO dilution at 1:1000 vol/vol) served as negative control. Anti-mTLR5 neutralizing IgG antibody was obtained from InvivoGen.

\section{Mice and cell lines}

C57BL/6 (wild-type, WT) mice were obtained from the Charité animal facility, Berlin, Germany, or purchased from Charles River Laboratory (Wilmington, MA, USA). Tlr5 ${ }^{-/-}$(B6.129S1-Tlr5 ${ }^{\text {tm1Flv }} / \mathrm{J}$ (Tlr5, stock no. 008377)) mice were bred at the animal facility of the Department of Veterinary Medicine, Robert-von-Ostertag Haus, Freie Universität Berlin, Germany, from a line originally developed in the S. Akira laboratory [62]. $T l r 2 / 4^{-/-}$mice were bred at the Charité animal facility, Berlin, Germany. Animals were maintained and handled in accordance with the German Animal Protection Law and approved by the
Regional Office for Health and Social Services in Berlin (Landesamt für Gesundheit und Soziales - LAGeSo, Berlin, Germany).

Oli-neu cells were generously provided by Dr. J. Trotter (Institute of Molecular Biology, Johannes GutenbergUniversity, Mainz, Germany [11]) and were cultured in Dulbecco's Modified Eagle Medium (DMEM) supplemented with $10 \%$ fetal bovine serum (FBS) and $1 \%$ penicillin/streptomycin (DMEM complete; all obtained from Invitrogen, Darmstadt, Germany).

Mouse glioma (GL) 261 cells (Charles River Laboratory, Wilmington, MA, USA) were lentivirally transduced for fluorescence labeling. Briefly, mCherry gene was cloned into a lentiviral vector on a pRRL backbone (https ://www.addgene.org/12252/), downstream of the MP71 promoter. After production of viral particles, GL261 cells were transduced at an MOI (multiplicity of infection) of 1 for $24 \mathrm{~h}$ using Roswell Park Memorial Institute (RPMI) medium supplemented with $10 \%$ fetal calf serum (FCS), $2 \%$ glutamine, $1 \%$ penicillin/streptomycin, and $0.4 \mathrm{mg} /$ ml polybrene (all obtained from Merck, Darmstadt, Germany). Transduction was stopped by adding fresh medium. MCherry-labeled GL261 cells were selected via FACS cell sorting and frozen until further use.

\section{Primary cell cultures of microglia, astrocytes, and neurons}

Neonatal primary microglia cultures were prepared from cerebral cortex and midbrain of newborn male and female P0-P3 C57BL/6, Tlr $5^{-/-}$, or $T l r 2 / 4^{-/-}$mice, as described previously $[40,55]$. In brief, forebrain was freed of blood vessels and meninges. Cortical tissue was dissociated by a fire-polished pipette using $3 \mathrm{ml}$ of $2.5 \%$ trypsin for 2 min and washed twice with phosphatebuffered saline (PBS). Mixed glial cells were cultured for 9-12 d in DMEM (Invitrogen, Darmstadt, Germany) supplemented with $10 \%$ FCS and 1\% penicillin/streptomycin (Gibco, New York, USA), with medium change every third day. Microglial cells were separated from the underlying glial layer by gentle shaking of the flasks for $1 \mathrm{~h}$ at $37{ }^{\circ} \mathrm{C}$ in $5 \% \mathrm{CO}_{2}$ humidified atmosphere on a shaker (100 rpm) and plated (for densities, see specific experimental approaches below). Resulting cell cultures usually contained $>95 \%$ microglia, as detected by isolectin b4 (IB4) staining (for details see below). Cells were maintained at $37{ }^{\circ} \mathrm{C}$ in $5 \% \mathrm{CO}_{2}$ humidified atmosphere.

Microglia from adult mice were prepared as described previously [54]. In short, brains derived from P49-P56 male mice were freed of blood vessels and meninges, mechanically dissociated, and digested with $2.5 \%$ trypsin and $1 \mathrm{mg} / \mathrm{ml}$ DNase (Roche Diagnostics, Mannheim, Germany). After further dissociation, cells were plated on a confluent monolayer of P0-P2 astrocytes in $75-\mathrm{cm}^{2}$ flasks. The feeding astrocytic layer was depleted of 
neonatal microglia using clodronate $(200 \mu \mathrm{g} / \mathrm{ml})$ before plating the microglial cells (for densities, see specific experimental set-ups below). Mixed adult and neonatal glial cultures were maintained in fresh DMEM, supplemented as described above, and medium was changed every third day, followed by addition of 33\% L292-conditioned medium at day 7 . After a further week, cells were shaken off and used for experiments within 24-48 h.

Cultures of cortical neurons were generated from forebrains of E17 mice, as described previously [40]. In brief, brains were separated from blood vessels, meninges, and cerebellum. Cortical tissue was treated with $500 \mu \mathrm{l}$ of $2.5 \%$ trypsin (Gibco, New York, USA) for $20 \mathrm{~min}$ at $37^{\circ} \mathrm{C}$. Trypsin activity was stopped by $4 \mathrm{ml}$ FBS (Invitrogen, Darmstadt, Germany). Thereafter, cells were washed with PBS and incubated with $100 \mu \mathrm{l}$ DNase $(1 \mathrm{mg} / \mathrm{ml}$; Roche Diagnostics, Mannheim, Germany) for $1 \mathrm{~min}$. Subsequently, cells were washed, centrifuged, and seeded on poly-D-lysine-coated (Sigma-Aldrich, St. Louis, USA) glass coverslips with a diameter of $12 \mathrm{~mm}$, at a density of 500,000 cells/well of a 24-well-plate, unless stated otherwise, with Neurobasal Medium (Gibco) supplemented with 1\% L-Glutamin, $1 \%$ penicillin/streptomycin, and 2\% B27 supplement (all obtained from Gibco, New York, USA). Cells were maintained at $37{ }^{\circ} \mathrm{C}$ in $5 \% \mathrm{CO}_{2}$ humidified atmosphere. On the following day, half of media was replaced, and cells were incubated for additional $48 \mathrm{~h}$ before starting experiments.

Primary astrocytes were isolated, as previously described [39]. In detail, mixed glial cultures were prepared from mouse brains, as described above (see neonatal primary microglia). After separation of microglial cells from the underlying glial layer by gentle shaking of the flasks for $1 \mathrm{~h}$ at $37^{\circ} \mathrm{C}$ on a shaker (100 rpm), cells were trypsinized (2.5\%), and subsequently plated at a density of 80,000 cells/well of a 24-well-plate for immunocytochemical analysis.

For microglia/neuron co-culture experiments half of the medium of 500,000 cultured neurons was replaced by DMEM containing 62,500 microglia (ratio 8:1) at day 3 after plating. On the following day, cultures were used for experiments.

\section{Multiplex immune assay}

Detection of TNF- $\alpha$, IL-6, IL-10, IL-1 $\beta$, GRO- $\alpha$ (CXCL1), macrophage inflammatory protein 2 (MIP-2 or CXCL2) and RANTES (CCL5) in $50 \mu \mathrm{l}$ supernatant collected from microglial cell cultures (density of 30,000/200 $\mu \mathrm{l}$ medium/well of a 96-well-plate) stimulated over time with flagellin was performed using the ProcartPlex mouse Multiplex Immunoassay Mix \& Match (Affymetrix eBioscience, Vienna, Austria) according to the manufacturer's manual. Briefly, the magnetic bead-based assay enables the simultaneous detection and quantification of multiple proteins in a single sample. Prior to incubation, samples were vortexed followed by centrifugation to remove particles. Proteins were detected using Luminex 200. Analysis was performed using Bioplex System Software 4.0 (Bio-Rad, Hercules, CA, USA).

\section{Nitric oxide release assay}

The amount of nitric oxide (NO) was determined using the colorimetric Griess reaction (Sigma-Aldrich, St. Louis, MO, USA), as previously described [41]. In detail, primary neonatal cultured microglia were seeded in a 96-well-plate at a density of 30,000/well. Cells were incubated in DMEM complete (see above) for $24 \mathrm{~h}$ in a total volume of $200 \mu \mathrm{l} /$ well. Flagellin was added at a concentration of $100 \mathrm{ng} / \mathrm{ml}$. $100 \mathrm{ng} / \mathrm{ml}$ LPS was used as positive control. After $24 \mathrm{~h}, 100 \mu \mathrm{l}$ of supernatant were transferred to a fresh 96-well-plate. Solution A (100 mg naphthylethylene in $50 \mathrm{ml}$ aqua dest.) and solution $\mathrm{B}(1 \mathrm{~g}$ sulfanilamide and $6 \mathrm{ml} 85 \% \mathrm{H}_{3} \mathrm{PO}_{4}$ in $44 \mathrm{ml}$ aqua dest.) were mixed at the ratio of 1:1 shortly before use. Subsequently, the mixed solution was added to the wells containing the microglial supernatant at 1:1 ratio. A nitrite standard curve was prepared. Absorbance was measured at $550 \mathrm{~nm}$.

\section{Agarose spot assay}

Agarose spot assay for chemotactic invasion was performed, as previously described [63]. In summary, $0.1 \mathrm{~g}$ of low-melting point agarose (Promega, Madison, WI, USA) was diluted in $20 \mathrm{ml}$ of PBS originating a $0.5 \%$ agarose solution. Subsequently, the solution was heated until boiling and then cooled down to $40^{\circ} \mathrm{C}$. Afterwards, $90 \mu \mathrm{l}$ of agarose solution were mixed with $10 \mu \mathrm{l}$ of PBS with or without flagellin at indicated doses in a $0.5 \mathrm{ml}$ Eppendorf tube. Ten $\mu \mathrm{l}$ of the mixed solution were plated onto 35- mm-glass-bottomed dishes (Mattek Corporation, Ahland, MA, USA) and were cooled down for $10 \mathrm{~min}$ at $4{ }^{\circ} \mathrm{C}$. Four spots were pipetted in one dish, of which two contained PBS only and two contained PBS with flagellin. 500,000 microglial cells were plated onto the dish in $2 \mathrm{ml}$ DMEM complete (see above) and incubated at $37^{\circ} \mathrm{C}$ in $5 \% \mathrm{CO}_{2}$ humidified atmosphere for $3 \mathrm{~h}$. Subsequently, cells inside the spot were quantified by microscopy. To assess microglial motility versus chemotaxis, flagellin was additionally applied to the medium. For chemotaxis assays, flagellin was only present within the spot. Values are expressed as the average obtained from 6 dishes. When inhibitors (LY294002, 25 or $50 \mu \mathrm{M}$; Wortmannin, 0.1 or $1 \mu \mathrm{M}$; rapamycin, $100 \mu \mathrm{M}$; Akt inhibitor IV; 1 or 10 $\mu \mathrm{M})$ were added, cells were pre-treated for $30 \mathrm{~min}$ before plated onto the dish. 


\section{Boyden chamber assay}

Flagellin-induced chemotaxis was tested using a 48-wellmicrochemotaxis Boyden chamber (Neuroprobe, Bethesda, MD, USA). Upper and lower wells were separated by a polycarbonate filter $(8 \mu \mathrm{m}$ pore size; Poretics, Livermore, CA, USA). 20,000-40,000 microglial cells in $50 \mu \mathrm{l}$ of serum-free DMEM were added to the upper compartment, while lower wells contained flagellin in serum-free DMEM. Serum-free DMEM alone was used as control. For signaling inhibition experiments, cells were pre-treated with PI3K inhibitors (LY294002; 25 or $50 \mu \mathrm{M}$; Wortmannin; 0.1 or $1 \mu \mathrm{M})$, mTOR inhibitor (rapamycin; 10 or $100 \mu \mathrm{M}$ ), and with anti-mTLR5 antibody $(1 \mu \mathrm{g} / \mathrm{ml})$ for $30 \mathrm{~min}$ on ice before added to the upper compartment. The chamber was incubated at $37{ }^{\circ} \mathrm{C}$ and $5 \% \mathrm{CO}_{2}$ for $6 \mathrm{~h}$. Cells remaining on the upper surface of the membrane were removed by wiping, while cells in the lower compartment were fixed in methanol for $10 \mathrm{~min}$ and subjected to Diff-Quik stain (Medion Grifols Diagnostics AG, Duedingen, Switzerland). Rate of microglial migration was calculated counting cells in 4 random fields of each well using a $20 \times$ bright-field objective. For each condition, 2-4 fields in 4-8 wells were analyzed. Under control conditions, $\sim 40-80$ cells were present per field, and numbers of cells in each field were normalized to the average derived from control condition (set to $100 \%$ ).

\section{Flow cytometry-based phagocytosis assay}

After isolation of microglia as described above, cells were resuspended in DMEM (Thermo Fisher Scientific, Waltham, MA, USA) supplemented with 10\% FCS and $2 \mathrm{ml} \mathrm{L}$-glutamine at $37{ }^{\circ} \mathrm{C}$. Microglial cells were seeded onto primary cultured neonatal astrocytes overnight, as described previously [46]. Fluoresbrite Carboxylate Micropheres (BrightBlue, $4.5 \mu \mathrm{m}$ ) were coated with $5 \%$ FCS for $30 \mathrm{~min}$ at room temperature on a shaker at $1000 \mathrm{rpm}$. Beads were resuspended in Hank's balanced salt solution at a final concentration of $2 \times 10^{6}$ beads per $\mathrm{ml}$. Microglia-astrocyte co-cultures were washed once with Hank's balanced salt solution before $1 \mathrm{ml}$ bead solution was applied. Cells were incubated with beads for $30 \mathrm{~min}$ at $37{ }^{\circ} \mathrm{C}$ in $5 \% \mathrm{CO}_{2}$ humidified atmosphere. Afterwards, they were washed in fluorescence-activated cell sorting buffer. Cells were stained with CD11b antibody (1:50; eBioscience, San Diego, CA, USA) for $15 \mathrm{~min}$ at $4{ }^{\circ} \mathrm{C}$. After staining, cells were washed in fluorescenceactivated cell sorting buffer and pulled down at $500 \mathrm{~g}$ for $5 \mathrm{~min}$. Cells were resuspended in propidium iodide solution (ratio of 1:1000 in fluorescence-activated cell sorting buffer) to stain dead cells. Stained cells were transferred to a BD LSRFortessa Flow cytometer (BD Bioscience, Heidelberg, Germany). The phagocytic index implements the total number of cells that phagocytosed, and the number of beads taken up by a given cell. Data were analyzed using FlowJo v10 software (Tree Star, Ashland, OR, USA).

\section{Toxicity assay in vitro}

For toxicity studies, indicated amounts of flagellin and other reagents were added to neuron/microglia co-cultures (ratio 8:1; 500,000 neurons and 62,500 microglial cells per well of a 24-well-plate) or isolated neurons (500,000 neurons per well of a 24-well-plate) for various time periods, as indicated. Control cultures remained unstimulated. LPS (100 ng/ml) served as positive control for microglia-mediated neurodegeneration in co-cultures. Loxoribine $(1 \mathrm{mM})$ served as positive control for TLR7-mediated apoptosis of neurons. For each condition, experiments were performed in duplicates. NeuNand TUNEL-positive cells (in situ Cell Death Detection Kit, TMR red or Fluorescein, Roche Diagnostics, Mannheim, Germany) were counted analyzing 5 fields per coverslip. Control condition was set to $100 \%$. Numbers of NeuN- and TUNEL-positive cells observed for each condition were compared with control.

\section{Intrathecal injection}

Intrathecal injection of 6-8-week-old male C57BL/6 mice with $1 \mu \mathrm{g}$ flagellin in a volume of $40 \mu \mathrm{l}$ PBS was performed as described previously $[25,36]$. PBS alone served as control. After transcardial perfusion with $4 \%$ paraformaldehyde, brains were removed and cryoprotected in $30 \%$ sucrose. Neuronal survival and microglial numbers were analyzed by blinded quantification of cortical NeuN-/active caspase-3-positive cells and Iba1-positive cells, respectively, in 6 fields (magnification x60) of 5 representative sections of each brain (see below).

\section{Glioma ex vivo model}

Organotypic brain slice preparation was performed as previously described [45]. Brains from P14-P16 C57BL/6 and $T l r 5^{-1-}$ mice were placed in ice-cold PBS. Cerebellum and olfactory bulb were removed and the forebrain cut in the coronal plane into $250-\mu \mathrm{m}$-sections using a vibratome (Microm HM650V, Thermo Scientific, Waltham, MA, USA). Brain slices were transferred onto $0.4 \mu \mathrm{m}$-polycarbonate membranes of a transwell insert (Falcon model 3090, Becton-Dickinson, Franklin Lakes, NJ, USA), which was inserted into a 6-well-plate (Falcon model 3502, Becton-Dickinson, Franklin Lakes, NJ, USA). Brain slices were incubated in $1 \mathrm{ml}$ of culture medium per well containing DMEM supplemented with 10\% heat-inactivated FBS (Gibco, Thermo Fisher Scientific, Waltham, MA, USA), $0.2 \mathrm{mM}$ glutamine, and $1 \%$ penicillin/streptomycin). After overnight equilibration, 
slices were incubated with medium containing 25\% FBS (Atlanta Biological, Norcross, GA, USA), $50 \mathrm{mM}$ sodium bicarbonate, $2 \%$ glutamine, $25 \%$ Hank's balanced salt solution, $1 \mu \mathrm{g} / \mathrm{ml}$ insulin, $5 \mathrm{mM}$ Tris (all from Life Technologies, Carlsbad, CA, USA), $2.46 \mathrm{mg} / \mathrm{ml}$ glucose (Braun, Melsungen, Germany), $0.8 \mathrm{mg} / \mathrm{ml}$ vitamin C, 100 $\mathrm{U} / \mathrm{ml}$ penicillin, and $100 \mu \mathrm{g} / \mathrm{ml}$ streptomycin (all from Sigma-Aldrich, St. Louis, MO, USA) in DMEM (Gibco, Thermo Fisher Scientific, Waltham, MA, USA). Slices were cultured for $5 \mathrm{~d}$ with medium change every $2 \mathrm{~d}$. For flagellin stimulation experiments, flagellin $(100 \mathrm{ng} / \mathrm{ml})$ was added to the medium on day 1 and 3 after slicing.

The day after sectioning, 5000 cultured mCherry GL261 glioma cells in a volume of $0.1 \mu \mathrm{l}$ were injected into the slices using a microsyringe mounted to a micromanipulator. An injection canal was formed that reached $150 \mu \mathrm{m}$ deep into the $250-\mu \mathrm{m}$-thick slice. The needle was then retracted by $50 \mu \mathrm{m}$, thereby forming an injection cavity of about $50 \mu \mathrm{m}$ depth. The tumor cell suspension was slowly inoculated into the cavity, and the syringe was pulled out. To ensure identical experimental conditions, gliomas were always inoculated in the striatal area of both hemispheres.

On day 4 after injection organotypic brain slices were fixed with 4\% PFA for $1 \mathrm{~h}$, washed with PBS and stained with Hoechst (1:4750) before being washed again and mounted. Tumor volumes were determined by confocal microscopy (Leica TCS SPE, Leica Microsystems, Wetzlar, Germany). Images were acquired with a 20x oil immersion objective using a $\mathrm{z}$-stack with a 2 - $\mu \mathrm{m}$-stepsize interval and tile scan mode. Tumor volume was assessed using Imaris 9.2 (Bitplane, Zürich, Switzerland). Tumor volumes were 3D-rendered by application of $1 \mu \mathrm{m}$ object detail, 15-threshold background, and 1000 tridimensional pixels (voxels). The surface objects obtained were unified in one single object, and values for volume mean were extracted.

\section{Immunocytochemistry, immunohistochemistry, and TUNEL assay}

Immunostaining was performed as described previously [41]. In detail, representative brain sections (level 1: interaural $6.60 \mathrm{~mm}$; level 2: $5.34 \mathrm{~mm}$; level 3: $3.94 \mathrm{~mm}$; level 4: $1.86 \mathrm{~mm}$; level $5:-0.08 \mathrm{~mm}$ ) or cell cultures (microglia at a density of $80,000 /$ well, astrocytes at a density of $80,000 /$ well, neurons at a density of 300,000/well; all cell types were seeded on 12-mm-glass cover slips in a 24-well-plate) were fixed with 4\% PFA (200 $\mu \mathrm{l})$, washed $3 \mathrm{x}$ with $200 \mu \mathrm{PBS}$, and treated with blocking solution (5\% normal goat serum (NGS) for brain sections or 2\% NGS for cell cultures; $0.2 \%$ TritonX-100) for $1 \mathrm{~h}$. The following primary antibodies were used: TLR5 (clone 19D759.2, ab13876, Abcam, Cambridge, UK, 1:200), NeuN (ABN
78, Sigma-Aldrich, St. Louis, MO, USA, 1:500), active caspase-3 (\#9661, Asp175, Cell Signaling Technology, 1:500), S100 $\beta$ (ab227914; Abcam, Cambridge, UK, 1:250) and Iba1 (\#019-19741, Wako, 1:500). Isolectin b 4 (IB4) was obtained from Invitrogen (Carlsbad, CA, USA). Cells and brain sections were incubated with the respective antibody overnight at $4{ }^{\circ} \mathrm{C}$. Subsequently, they were washed 3x with PBS incubated with the relevant secondary antibody (\# A-11001, Alexa Fluor 488 goat antimouse IgG; \# A-11004, Alexa Fluor 568 goat anti-mouse IgG; \# A-11008, Alexa Fluor 488 goat anti-rabbit IgG; \# A-11011, Alexa Fluor 568 goat anti-rabbit IgG; all used in 1:500 dilution and purchased from Invitrogen, Eugene, OR, USA) for $1 \mathrm{~h}$ at room temperature. Finally, nuclei were stained with 4',6-diamidino-2-phenylindole (DAPI) solution (1:10,000, D9542, Sigma-Aldrich, St. Louis, MO, USA) for $1 \mathrm{~min}$ and washed $3 \mathrm{x}$ in PBS. Coverslips were attached onto glass slides using 1 drop of ImmuMount (\#9990402; Thermo Scientific, Waltham, MA, USA)/ coverslip.

Numbers of neurons and microglia in the cerebral cortex within brain sections were assessed by blinded quantification of NeuN- and Iba1-positive cells in 3 fields per hemisphere (x60 magnification) at level 4 of the 5 representative sections of each brain (see above). For analysis of apoptosis, brain sections were stained by active caspase-3 and DAPI and quantified as described for NeuNand Iba1-stained cells above. The mean was calculated, which is expressed as NeuN-positive, Iba1-positive, or active caspase-3-positive cells per $\mathrm{mm}^{2}$. Each group is displayed with the median. An Olympus BX51 microscope and a Leica TCS SL confocal laser-scanning microscope were used.

\section{Western blot}

Western blot analysis was performed using whole lysates of $10^{6}$ cultured microglia per dish. Before collection, cells were washed with cold PBS. Radioimmunoprecipitation assay (RIPA) buffer was used as lysis buffer containing $1 \%$ NP-40, $0.5 \%$ sodium deoxycholate, and $0.1 \%$ SDS dissolved in 1\% TBS buffer. Protease inhibitor cocktail (Roche, Grenzach-Wyhlen, Germany) and phosphatase inhibitor mixture (Sigma-Aldrich, Darmstadt, Germany) were added to RIPA buffer before cell lysis. Cells were homogenized by a syringe needle, followed by centrifugation at 15,000 rpm for $10 \mathrm{~min}$ to remove insoluble cell debris. Protein concentration was measured by BCA protein assay kit (Thermo Fisher Scientific, Waltham, MA, USA), and a total of $20 \mu \mathrm{g}$ protein was separated by $10 \%$ SDS-PAGE and subsequently electrophoretically transferred onto polyvinylidene difluoride (PVDF) membranes (Bio-Rad Laboratories, Hercules, CA, USA). After protein transfer, PVDF membranes were blocked 


\begin{abstract}
(See figure on next page.)
Fig. 1 TLR5 is constitutively expressed in microglia, and its activation triggers PDK1 and Akt phosphorylation in a PI3K-dependent manner. a Relative TLR5 expression levels were assessed in primary neonatal microglia, primary adult microglia, primary astrocytes, and primary cortical neurons isolated from C57BL/6 mice, as well as Oli-neu cells by quantitative RT-PCR (fold-change compared to neurons). TATA sequence binding protein (TBP) was used as housekeeping control $(n=3)$. Results are represented as mean \pm SD. Data were analyzed by one-way ANOVA followed by Newman-Keuls test. ${ }^{*} P<0.05$; ${ }^{*} P<0.01$. b Cultured neonatal microglia, astrocytes, and neurons from C57BL/6 (WT) mice, as well as microglia from T/r $5^{-1-}$ mice were stained with antibody directed against TLR5 and co-stained with Iba1, S100ß, or NeuN antibody serving as microglial, astrocyte, and neuronal marker, respectively. Scale bar, $10 \mu \mathrm{m}$. c Western blot analysis of microglial lysates using antibodies against p-Akt and total Akt after incubation of microglia with $100 \mathrm{ng} / \mathrm{ml}$ flagellin (FLA) for 0, 5, 15, 30, or $60 \mathrm{~min}(n=3)$. Representative blots are shown in the upper panel. The graph depicts the average intensity ratio of the bands compared to control (lower panel). Data are expressed as mean \pm SEM and were analyzed by one-way ANOVA followed by Dunnett's post hoc test. ${ }^{* *} P<0.01$ vs. control. $\mathbf{d}$ Western blot analysis of FLA-mediated Akt phosphorylation after treatment of microglia with LY294002 (25 and $50 \mu \mathrm{M}$ ), Wortmannin (0.1 and $1 \mu \mathrm{M})$, and anti-mTLR5-lgG ( $1 \mu \mathrm{g} / \mathrm{ml})$ (upper panel, $n=3$ ). The graph shows the average intensity ratio of the bands compared to control (lower panel). e Western blot analysis of microglial lysates with antibodies against p-PDK1 and $\beta$-actin after incubation of microglia with $100 \mathrm{ng} / \mathrm{ml} \mathrm{FLA,} \mathrm{FLA} \mathrm{plus} \mathrm{LY294002} \mathrm{(25} \mathrm{and} 50 \mu \mathrm{M}$ ), FLA plus Wortmannin (0.1 and $1 \mu \mathrm{M})$, and FLA plus anti-mTLR5-lgG $(1 \mu \mathrm{g} / \mathrm{ml}$ ) (upper panel, $n=3)$. The graph depicts average intensity ratio of the bands compared to control (lower panel). Data are expressed as mean \pm SEM and were analyzed by one-way ANOVA followed by Tukey's post hoc test. ${ }^{* *} P<0.01$ vs. control; ${ }^{\#} P<0.01$ vs. FLA. d, e DMSO-containing DMEM served as control, while FLA was solved in DMSO-containing DMEM
\end{abstract}

with Tris-buffered saline containing $5 \%$ bovine serum albumin (BSA) for $1 \mathrm{~h}$ at room temperature. Membranes were then incubated at $4{ }^{\circ} \mathrm{C}$ overnight with antibodies against phospho-AKT (S-473) and Akt purchased from Cell Signaling Technology (Danvers, MA, USA). Membranes were washed and incubated with anti-rabbit IgG secondary antibody (Cell Signaling Technology, Danvers, MA, USA) at room temperature for $2 \mathrm{~h}$. Protein signal transferred onto the PVDF membrane was visualized by ECL Prime Western Blotting Detection Reagent (GE Healthcare, Buckinghamshire, UK) using the Chemi Doc XRS system (Bio-Rad Laboratories, Hercules, CA, USA). Quantification of signals was assessed using Image J software.

\section{Quantitative real-time PCR}

Primary neonatal microglia, adult microglia, astrocytes, neurons, or Oli-neu cells were seeded at a density of $10^{6}$ cells per dish in a 6-well-plate. After $24 \mathrm{~h}$, cells were stimulated with flagellin $(100 \mathrm{ng} / \mathrm{ml})$ for $24 \mathrm{~h}$. Subsequently, cell lysates were collected and RNA was extracted, followed by cDNA synthesis and quantitative PCR expression analysis. Primers directed against TLR5 and TNF- $\alpha$ were purchased from QIAGEN (Hilden, Germany). For details of the qPCR cycle program used please refer to the Thermo Scientific Maxima SYBR Green/ROX qPCR Master Mix manual.

\section{Statistics}

Data are expressed as mean \pm SEM or \pm SD. Statistical differences between selected groups were determined using Dunnett's or Tukey's multiple comparison test after one-way ANOVA, Kruskal-Wallis test followed by Dunn's multiple comparison post hoc test, or Student's $t$ test, as indicated. Statistical differences were considered significant when $P<0.05$.

\section{Results}

In the CNS, TLR5 is primarily expressed in microglia, and its activation triggers PDK1 and Akt phosphorylation in a PI3K-dependent fashion

TLR5 was previously reported being expressed in microglia and dorsal root ganglion neurons [52, 64]. We compared expression levels of TLR5 in murine CNS glial cells and neurons by quantitative RT-PCR. Among the different CNS cell types (for images of cultured primary microglia, neurons, and astrocytes, please refer to Additional file 1), microglia expressed the highest levels of TLR5, of which adult microglia expressed higher TLR5 expression levels than neonatal microglia. Compared to microglia, astrocytes and Oli-neu cells, a mouse oligodendroglial precursor line, expressed low levels of TLR5, while this receptor was barely detectable in primary cortical neurons (Fig. 1a). TLR5 protein was readily detectable in cultured neonatal microglia, but also in astrocytes, although to a much lesser extent, by immunocytochemistry. In contrast, TLR5 protein expression was not detected in cortical neurons (Fig. 1b). Specificity of the antibody to TLR5 was confirmed by analyzing microglia from $T l r 5^{-/-}$mice (Fig. 1b).

Flagellin-induced TLR5 activation was previously shown to induce PI3K, as evidenced by Akt phosphorylation, a downstream effector of PI3K and 3-phosphoinositide-dependent kinase-1 (PDK1), thereby mediating regulation of proinflammatory gene expression in epithelial cells $[51,67]$. To investigate this signaling pathway in microglia, we exposed neonatal microglia to flagellin and subsequently assessed their p-Akt expression by western blot. In response to flagellin, p-Akt expression was significantly increased after $30 \mathrm{~min}$ and decreased to control level at $60 \mathrm{~min}$ (Fig. 1c). Flagellin-induced Akt phosphorylation was abolished by the PI3K inhibitors LY294002 and Wortmannin (Fig. 1d). Furthermore, 


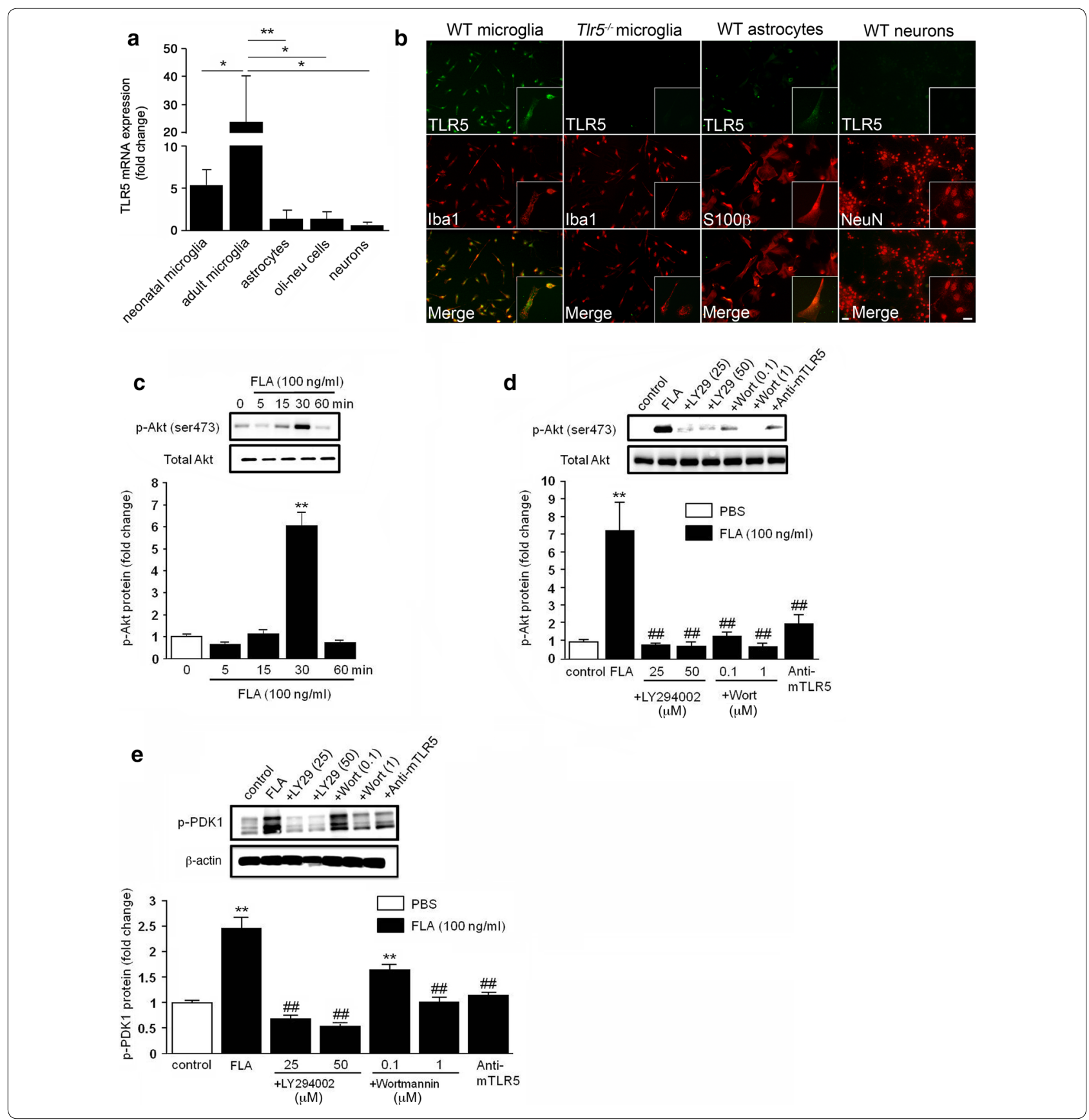

flagellin-induced Akt phosphorylation was dependent on functional TLR5, as TLR5-neutralizing antibody significantly diminished this response (Fig. 1d). Next, flagellin-treated microglia were analyzed for phosphorylated PDK1 (p-PDK1) expression. Western blot analysis revealed an increase in P-PDK1 expression in response to flagellin after $30 \mathrm{~min}$, and LY294002 and wortmannin significantly inhibited these effects (Fig. 1e). Employment of the TLR5-neutralizing antibody reduced levels of
p-PDK1, thereby confirming TLR5 as the signaling receptor in flagellin-induced PDK1 phosphorylation (Fig. 1e).

\section{Activation of TLR5 and subsequent PI3K/Akt/mTORC1 signaling in microglia results in the release of distinct inflammatory molecules}

Activation of various TLRs results in the release of inflammatory molecules including cytokines, chemokines, and nitric oxide (NO) from microglia [37]. 
However, the role of TLR5 in microglia in this context has not been explored. Thus, to determine the specific inflammatory response pattern induced by activation of microglial TLR5, we analyzed supernatants from neonatal wild-type (WT) and $T l r 5^{-/}$microglia incubated with $100 \mathrm{ng} / \mathrm{ml}$ flagellin after $24 \mathrm{~h}$ by multiplex immunoassay. Specific cytokines and chemokines were selected for analysis based on their relevance in the context of neuroinflammation and neurodegenerative diseases, as well as on their suitability as microglial activation markers $[23,50,58]$. LPS as the established TLR4 ligand served as positive control. TNF- $\alpha$, RANTES, MIP-2, IL-10, IL-6, and GRO- $\alpha$ were significantly released from WT microglia in response to flagellin, while IL-1 $\beta$ was not detected (Fig. 2a; for protein concentrations of detected cytokines/chemokines please refer to Additional file 2). Notably, LPS induced an enhanced MIP-2 response in $T l r 5^{-/-}$microglia compared to WT cells (Fig. 2a). Induction of all tested cytokines in flagellin-treated microglia required TLR5, as $\mathrm{Tlr}^{-1-}$ microglia failed to respond to flagellin (Fig. 2a). To assess dose-dependent effects, microglia were incubated with increasing doses of flagellin up to $1000 \mathrm{ng} / \mathrm{ml}$, and their supernatants were subsequently analyzed for selected cytokines by multiplex immunoassay. We observed a dose-dependent increase in TNF- $\alpha$, RANTES, MIP-2, and GRO- $\alpha$ in response to $10 \mathrm{ng} / \mathrm{ml}$ and $100 \mathrm{ng} / \mathrm{ml}$ flagellin compared to control condition. However, microglia exposed to $1000 \mathrm{ng} / \mathrm{ml}$ flagellin released diminished amounts of these cytokines compared to microglia responding to $100 \mathrm{ng} / \mathrm{ml}$ flagellin (Fig. 2b). This cytokine reduction observed at $1000 \mathrm{ng} / \mathrm{ml}$ flagellin was not due to potential flagellin-induced toxicity towards microglia, as quantification of IB4-positive cells and TUNEL staining of flagellin-treated cells did not indicate cellular injury or loss, even when microglia were exposed to doses up to $5 \mu \mathrm{g} / \mathrm{ml}$ flagellin (Additional file 3). Induction of cytokines, as indicated above, in $T l r 2 / 4^{-/-}$microglia was similar to that of WT cells after exposure to flagellin, excluding the possibility of relevant contamination of recombinant flagellin with LPS or TLR2 ligands (data not shown) and confirming the results derived from $\mathrm{Tlr}^{-/-}$microglia with respect to receptor specificity. Further, in contrast to LPS, flagellin did not induce NO production in microglia, as assessed by Griess assay (Fig. 2c).

To determine whether flagellin-induced release of cytokines from microglia requires PI3K/Akt signaling, microglia were incubated with flagellin in the presence or absence of LY294002 or Wortmannin for $6 \mathrm{~h}$, and mRNA expression levels of TNF- $\alpha$-a representative cytokine produced in activated microglia, were determined by quantitative RT-PCR. As expected, PI3K inhibitor treatment inhibited TNF- $\alpha$ mRNA expression in microglia exposed to flagellin (Fig. 2d). Likewise, presence of the mammalian target of rapamycin complex 1 (mTORC1) inhibitor rapamycin in microglial cultures prevented TNF- $\alpha$ expression in these cells (Fig. 2d). Pre-treatment with the TLR5-neutralizing antibody also diminished flagellin-induced TNF- $\alpha$ mRNA expression in microglia, thereby confirming TLR5 as the responsible immune receptor in this context (Fig. 2d).

Taken together, flagellin induced the release of distinct cytokines from microglia depending on TLR5 and PI3K/ Akt/mTORC1 signaling.

\section{Flagellin modulates microglial chemotaxis through TLR5 and PI3K/Akt/mTORC1 signaling}

To test the effect of flagellin on microglial migration, we analyzed cell accumulation in an agarose spot containing either flagellin or PBS serving as control (Fig. 3a). Microglia that had migrated into the agarose spot after $6 \mathrm{~h}$, were quantified. At a dose of $10 \mathrm{ng} / \mathrm{ml}$ flagellin, microglia did not significantly migrate, whereas the migration rate was significantly increased in response to $50 \mathrm{ng} / \mathrm{ml}$ and $100 \mathrm{ng} / \mathrm{ml}$ flagellin (Fig. 3b). To determine whether flagellin induces cell motility or directed migration, i.e. chemotaxis, $100 \mathrm{ng} / \mathrm{ml}$ flagellin was added either to the spot only, or to both spot and surrounding supernatant. Presence of flagellin increased microglial motility only in the presence of a gradient, as this effect was not observed when the gradient was absent (Fig. 3c). To confirm flagellin-induced chemotaxis, we tested microglia in a further migration assay, the Boyden chamber. Here, we observed similar effects as observed with the agarose spot assay. However, in the Boyden chamber, flagellin increased microglial migration at flagellin doses as low as $10 \mathrm{ng} / \mathrm{ml}$ (Fig. 3d). When flagellin was added to both top and bottom wells, thereby disseminating the gradient, no significant increase in microglial migration was detected (Fig. 3e). TLR5 served as the responsible receptor in flagellin-induced microglial chemotaxis, as pretreatment with the TLR5-neutralizing antibody inhibited migration in a dose-dependent fashion (Fig. 3f).

We reported previously that TLR2 and TLR7 agonistinduced microglial migration is inhibited by treatment with the PI3K inhibitors LY294002 and wortmannin, suggesting that signaling through PI3K contributes to TLRinduced microglial migration [29]. To analyze the PI3K/ Akt signaling pathway in flagellin-induced microglial chemotaxis, we again made use of the migration assays described above testing a dose of $100 \mathrm{ng} / \mathrm{ml}$ flagellin. In both agarose spot assay (Fig. 3g) and Boyden chamber (Fig. 3h) pre-treatment with LY294002 (at 25 and $50 \mu \mathrm{M})$ and Wortmannin (at 0.1 and $1 \mu \mathrm{M}$ ) for $30 \mathrm{~min}$ inhibited flagellin-induced microglial migration. To further characterize the signaling cascade through which 

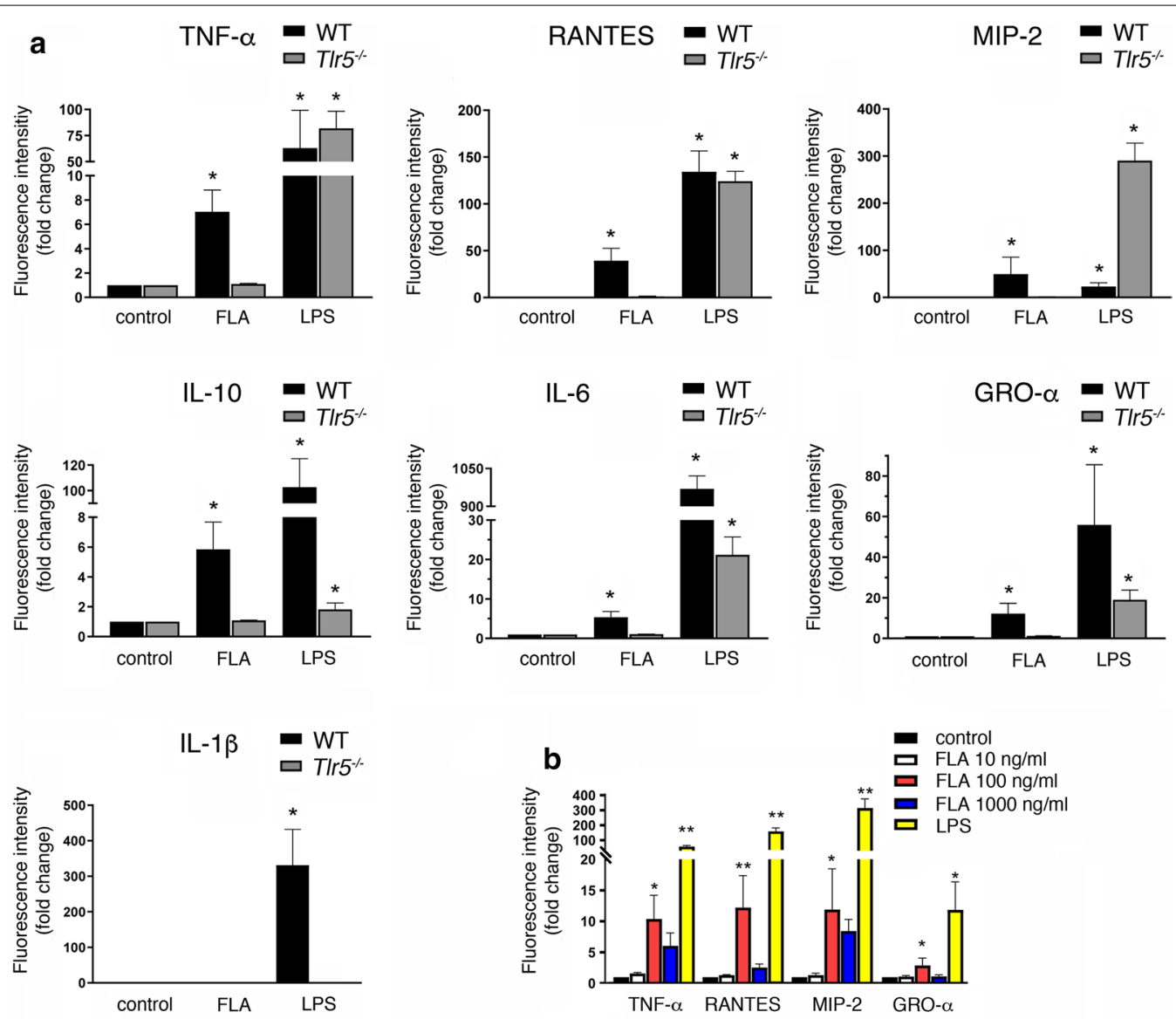

C

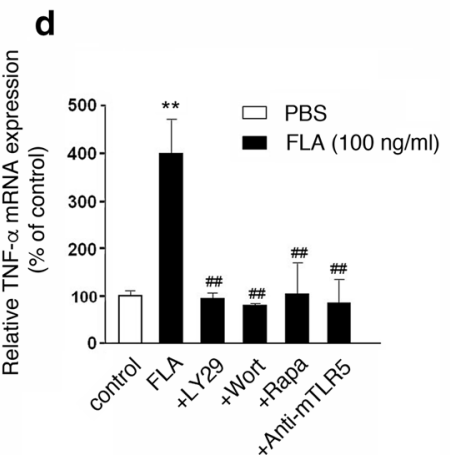

Fig. 2 Flagellin induces the release of cytokines and chemokines from microglia through TLR5 signaling. a Multiplex immunoassay was used to detect cytokines/chemokines, as indicated, in supernatants of cultured neonatal microglia from C57BL/6 (WT) and T/r5 ${ }^{-1-}$ mice in response to $100 \mathrm{ng} / \mathrm{ml}$ flagellin (FLA) after $24 \mathrm{~h}$. Unstimulated cells served as negative control, while LPS (100 ng/ml) was used as positive control ( $n=3$ ). b Supernatants of cultured neonatal WT microglia stimulated with $10 \mathrm{ng} / \mathrm{ml}, 100 \mathrm{ng} / \mathrm{ml}, 1000 \mathrm{ng} / \mathrm{ml} \mathrm{FLA}$, or $100 \mathrm{ng} / \mathrm{ml}$ LPS were analyzed for indicated cytokines/chemokines after $24 \mathrm{~h}$ by multiplex immunoassay. Unstimulated cells served as control $(n=3)$. Results are expressed as mean \pm SEM. Data were analyzed by Kruskal-Wallis test followed by Dunn's post hoc test. ${ }^{*} P<0.05 ;{ }^{* *} P<0.01$ vs. control. c Cultured neonatal WT microglia were stimulated with $100 \mathrm{ng} / \mathrm{ml} \mathrm{FLA} \mathrm{and/or} 100 \mathrm{ng} / \mathrm{ml}$ LPS for $24 \mathrm{~h}$, and supernatants were analyzed for NO using Griess assay $(n=3)$. Results are expressed as mean \pm SEM. Data were analyzed by Kruskal-Wallis test followed by Dunn's post hoc test. ${ }^{* *} P<0.01$ vs. control; n.s., not significant. d WT microglia were incubated with $100 \mathrm{ng} / \mathrm{ml} \mathrm{FLA} \mathrm{alone} \mathrm{or} \mathrm{in} \mathrm{combination} \mathrm{with} \mathrm{LY294002} \mathrm{(50} \mathrm{\mu M),} \mathrm{Wortmannin} \mathrm{(1} \mathrm{\mu M),} \mathrm{rapamycin}$ $(100 \mu \mathrm{M})$, or anti-mTLR5-lgG $(1 \mathrm{\mu g} / \mathrm{ml})$ for $6 \mathrm{~h}$. DMSO-containing DMEM served as control, while FLA was solved in DMSO-containing DMEM. Subsequently, quantitative RT-PCR using primers against TNF-a was performed. TBP served as housekeeping gene $(n=5)$. Results are expressed as normalized to control and are represented as mean \pm SD. Data were analyzed by one-way ANOVA followed by Tukey's post hoc test. ${ }^{* *} P<0.01$ vs. control; $\#$ \# $P 0.01$ vs. FLA 


\begin{abstract}
(See figure on next page.)
Fig. 3 Flagellin triggers chemotaxis, but not random motility in microglia, through TLR5 and PI3K/PDK1/Akt/mTORC1 signaling. a-c Microglial migration in response to flagellin (FLA) was analyzed by agarose spot assay. a Images of FLA- and PBS (control)-treated C57BL/6 microglia. Scale bar, $100 \mu \mathrm{m}$. b Various FLA doses, as indicated, were added either to the spot alone (gradient/black, $n=8$ ) or $\mathbf{c}$ to both the spot and the culture medium (no gradient/grey, $n=4$ ). PBS was used as negative control. Microglial migration was quantified after $6 \mathrm{~h}$ of FLA incubation. Results are expressed as mean $\pm S E M$. Data were analyzed by one-way ANOVA followed by Tukey's post hoc test. ${ }^{*} P<0.05 ;{ }^{* *} P<0.01$ vs. control; $\# \#<0.01$. d Microglial migration in response to FLA was analyzed by Boyden chamber assay. Images of C57BL/6 microglia plated in the upper compartment and treated with $100 \mathrm{ng} / \mathrm{ml}$ FLA. PBS served as control. Scale bar, $100 \mu \mathrm{m}$ (upper panel). Microglial migration in response to various FLA doses, as indicated, was quantified after $6 \mathrm{~h}$ (lower panel, $n=10$ ). Results are expressed as mean $\pm S E M$. Data were analyzed by one-way ANOVA followed by Dunnett's post hoc test. ${ }^{* *} P<0.01$ vs. control. e Quantification of microglia plated in both wells of the Boyden chamber lacking a gradient $(n=10)$. Results are expressed as mean \pm SEM. Data were analyzed by one-way ANOVA followed by Dunnett's post hoc test. n.S., not significant. $\mathbf{f}$ Agarose spot assay testing microglial migration, as described in $(\mathbf{a}, \mathbf{b})$ in the presence of various doses of mouse TLR5-neutralizing antibody (anti-mTLR5), as indicated $(n=4)$. Results are expressed as mean \pm SEM. Data were analyzed by one-way ANOVA followed by Dunnett's post hoc test. ${ }^{* *} P<0.01$ vs. control; ${ }^{\# \#} P<0.01$. g Agarose spot assay testing microglial migration, as described in $(\mathbf{a}, \mathbf{b})$ in the presence of LY294002 (25 and $50 \mu \mathrm{M})$ and Wortmannin $(0.1$ and $1 \mu \mathrm{M}), n=12$. Results are expressed as mean \pm SEM. Data were analyzed by one-way ANOVA followed by Tukey's post hoc test. ${ }^{* *} P<0.01$ vs. control; ${ }^{\#} P<0.01$ vs. FLA. $\mathbf{h}$ FLA-induced $(100 \mathrm{ng} / \mathrm{ml})$ microglial migration in the Boyden chamber in the presence of LY294002 (25 and $50 \mu \mathrm{M})$, Wortmannin $(0.1$ and $1 \mu \mathrm{M})$, rapamycin $(10$ and $100 \mu \mathrm{M})$, or anti-mTLR5-lgG $(1 \mu \mathrm{g} / \mathrm{ml}), n=12$. Results are expressed as mean \pm SEM. Data were analyzed by one-way ANOVA followed by Tukey's post hoc test. ${ }^{* *} P<0.01$ vs. control; ${ }^{\# \#} P<0.01$ vs. FLA. (i) FLA-induced $(100 \mathrm{ng} / \mathrm{ml})$ microglial migration tested by agarose spot assay in the presence of rapamycin $(10$ and $100 \mu \mathrm{M})$ or Akt inhibitor IV $(1 \mu \mathrm{M}), n=4$. Results

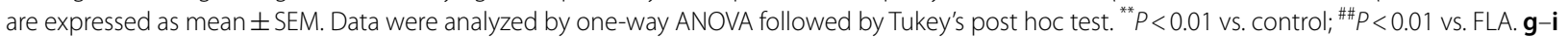
DMSO-containing DMEM served as control, while FLA was solved in DMSO-containing DMEM
\end{abstract}

PI3K regulates flagellin-induced migration, we included the established mTORC1 inhibitor rapamycin (at 10 and $100 \mu \mathrm{M})$ and Akt inhibitor IV $(1 \mu \mathrm{M})$ in the migration analysis. Pretreatment with both inhibitors for $30 \mathrm{~min}$ inhibited flagellin-induced microglial motility, suggesting that this process is dependent on Akt and mTORC1 signaling (Fig. 3h, i). TLR5 as the responsible receptor in flagellin-induced microglial migration (see Fig. 3f) was confirmed using the Boyden chamber assay as pretreatment with the TLR5-neutralizing antibody inhibited migration (Fig. 3h).

In summary, these results indicate that flagellin is a chemotactic signal for microglia mediated by TLR 5 and $\mathrm{PI} 3 \mathrm{~K} / \mathrm{Akt} / \mathrm{mTORC1}$ signaling.

\section{Microglial phagocytosis is enhanced in response to flagellin and dependent on TLR5 and PI3K/Akt/mTORC1 signaling}

To examine whether flagellin affects the phagocytic activity of microglia, we analyzed the uptake of fluorescent beads through flow cytometry. Fluorescent beads were added to microglia for $30 \mathrm{~min}$, and subsequently, cells were isolated and stained with CD11b antibody. Exposure to flagellin for 30 min significantly increased phagocytic activity of microglia. The number of cells containing one, two, and more beads were significantly increased in flagellin-exposed cell cultures, while the number of cells lacking beads decreased (Fig. 4a, b). This effect was completely abolished in the presence of LY294002, Wortmannin, and rapamycin, indicating that PI3K/Akt/mTORC1 signaling was required in flagellin-induced microglial phagocytosis. Furthermore, increased phagocytic activity of microglia in response to flagellin was dependent on TLR5, as TLR5-neutralizing antibody abolished this effect (Fig. 4b).

\section{In contrast to TLR 2/4/7, TLR5 does not mediate microglia-glioma interaction}

TLRs play an important role for the interaction of microglia with glioma cells promoting a pro-tumorigenic phenotype including TLR2, TLR4, and TLR7 signaling [18]. This has been substantiated by an ex vivo brain tumor model, in which mCherry-GL261 glioma cells were inoculated into brain slices [5, 12, 27]. Using this model, we explored whether TLR5 activation plays a role in glioma growth in brain slices derived from WT and Tlr $5^{-1-}$ mice. Tumor sizes were compared after $4 \mathrm{~d}$ post-injection. No significant differences with respect to tumor volume between WT and $\mathrm{Tlr} 5^{-/-}$mice were detected (Additional file 4a). Likewise, when mCherry-GL261 glioma cells injected into WT brain slices were exposed to flagellin for $4 \mathrm{~d}$, no significant impact on glioma growth was observed (Additional file 4b).

\section{Microglia exposed to flagellin contribute to neuronal apoptosis through TLR5}

Microglia can trigger neurodegeneration through TLRs including TLR2, TLR3, TLR4, TLR7, and TLR9 [6, 30, $36,38,40]$. To test whether activation of TLR5 in microglia affects neuronal survival, co-cultures of neurons and microglia derived from WT or $T l r 5^{-1-}$ mice were exposed to flagellin. Assessment of the relative neuronal viability revealed that flagellin induced neuronal loss (Fig. 5a) in a dose (Fig. 5b)- and time (Fig. 5c)-dependent manner. Under control conditions, microglia co-cultured with neurons did not significantly affect neuronal 


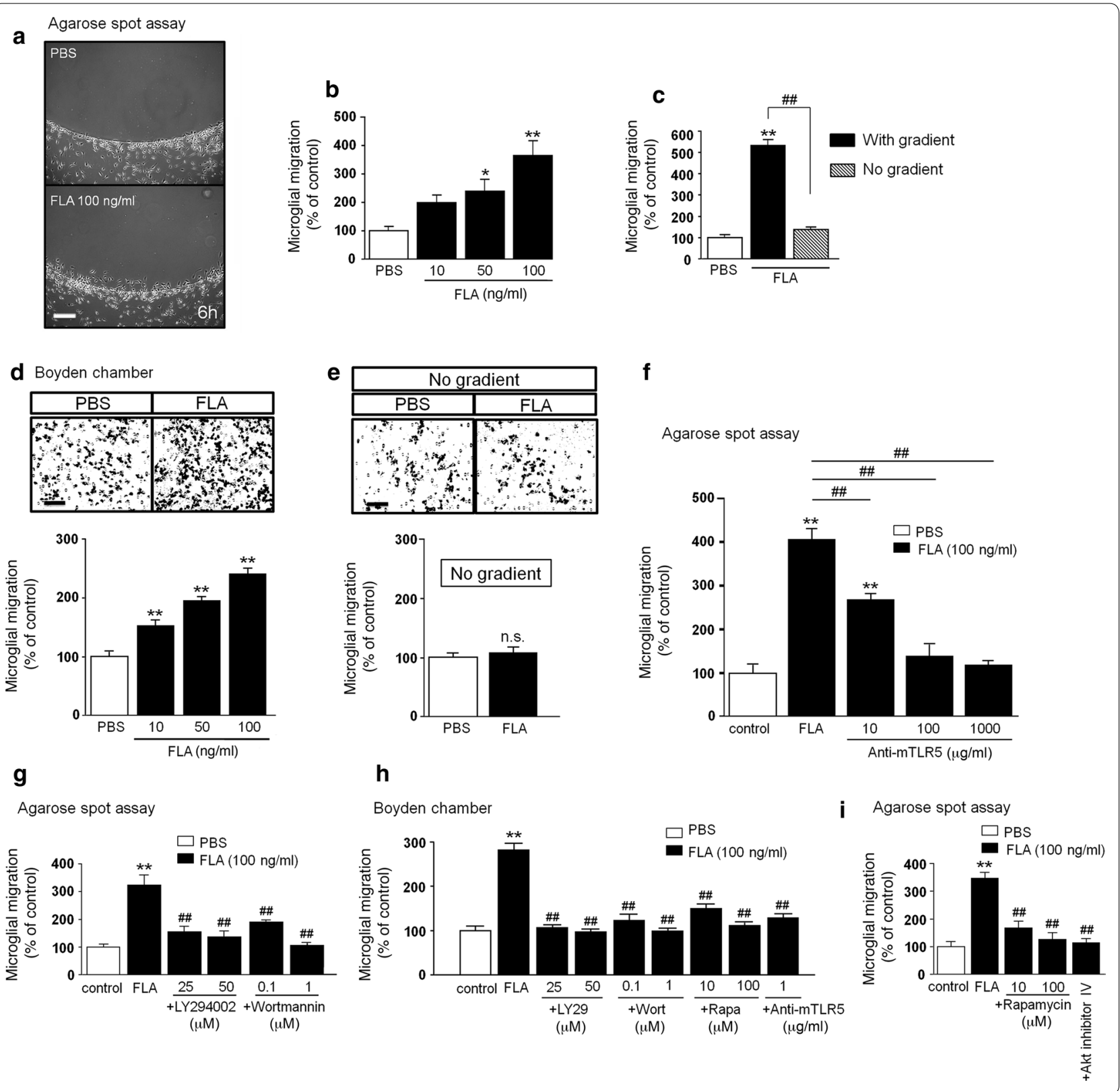

survival, and $1 \mathrm{ng} / \mathrm{ml}$ flagellin also had no significant toxic effect within $72 \mathrm{~h}$ (loss of NeuN-positive cells by $4.1 \%$ $( \pm 1.8, P=0.1443))$. In contrast, $10 \mathrm{ng} / \mathrm{ml}$ and $100 \mathrm{ng} / \mathrm{ml}$ flagellin induced neuronal loss by $19.2 \%( \pm 3.4, P=0.017)$ and $30.9 \%( \pm 4.1, P=0.0042)$, respectively, compared to control condition after $72 \mathrm{~h}$ (Fig. 5b). While exposure to $100 \mathrm{ng} / \mathrm{ml}$ flagellin did not significantly reduce neuronal viability within $12 \mathrm{~h}(15.2 \% \pm 2.3, P=0.2177$; data not shown), neuronal loss was observed after 1 d, $3 \mathrm{~d}$, and $5 \mathrm{~d}$ of flagellin treatment by $26.8 \%( \pm 12.0$, $P=0.0363), 30.9 \%( \pm 4.1, P=0.0153)$, and $32.0 \%$ ( \pm 7.9 , $P=0.0211$ ), compared to control, respectively (Fig. $5 \mathrm{c}$ ).
In accordance with this, flagellin treatment caused an increase in TUNEL-positive cells in neuronal cultures in the presence of WT microglia (Fig. 5d, e). Flagellininduced neurotoxicity required microglial TLR5, as neurons co-cultured with $\mathrm{Tlr} 5^{-/-}$microglia were protected from flagellin-induced neurotoxicity (Fig. $5 \mathrm{a}-\mathrm{c}$ ). To test whether this neurotoxicity requires microglia, we incubated purified cortical neurons with flagellin, LPS, which induces neuronal injury through microglial TLR4 in cocultures [40], or loxoribine, an established TLR7 ligand known to induce cell-autonomous neuronal apoptosis [36]. Assessment of the relative neuronal viability 

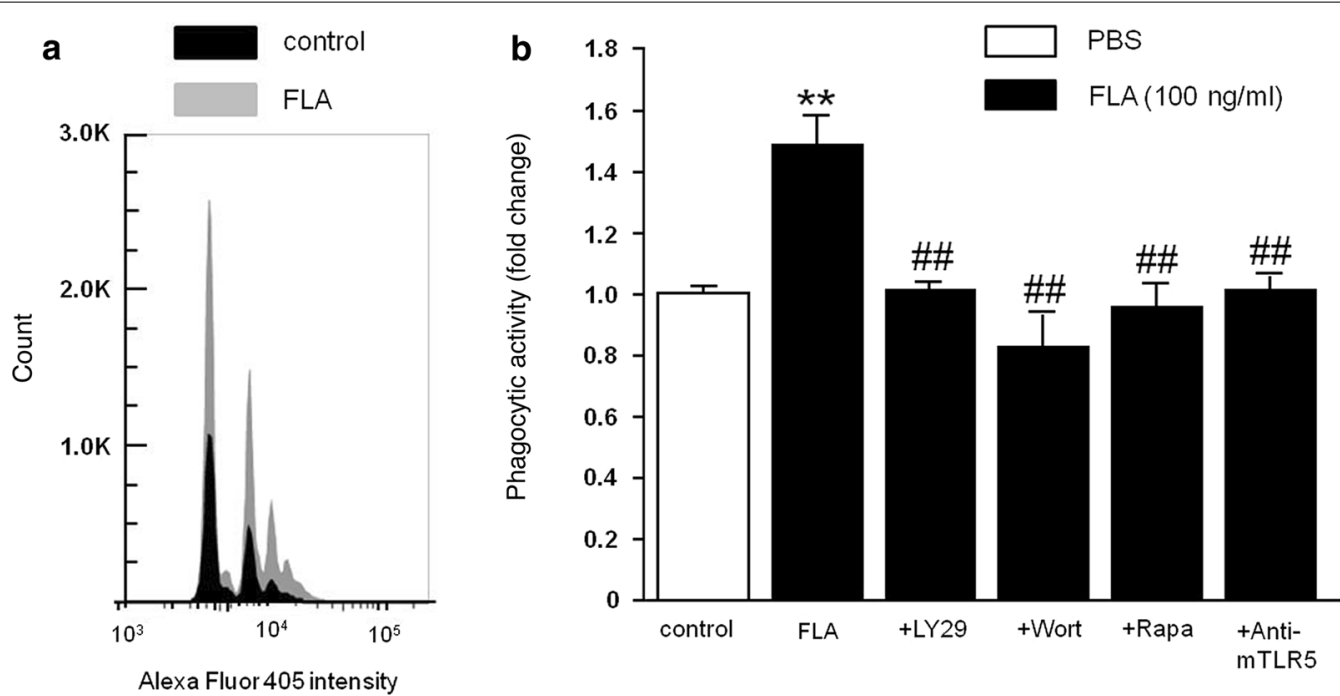

Fig. 4 Flagellin-induced microglial phagocytosis is mediated by TLR5 and the PI3K/PDK1/Akt/mTOR pathway. a Using FACS-based phagocytosis assay incorporation of Alexa Fluor 405-labelled beads into microglia was quantified. The image shows representative histograms, in which peaks represent the number of microglia that phagocytosed none or one to four beads in the absence (control, black) and presence of flagellin (FLA, $100 \mathrm{ng} / \mathrm{ml}$, gray). b The phagocytic index derived from the data shown in (a) was determined and normalized to control. In addition, FLA-treated microglia in the presence of LY294002 $(50 \mu \mathrm{M})$, Wortmannin $(1 \mu \mathrm{M})$, rapamycin $(100 \mu \mathrm{M})$, or anti-mTLR5-lgG $(1 \mu \mathrm{g} / \mathrm{ml})$ were tested $(n=4)$.

DMSO-containing DMEM served as control, while FLA was solved in DMSO-containing DMEM. Results are expressed as mean \pm SEM. Data were analyzed by one-way ANOVA followed by Tukey's post hoc test. ${ }^{* *} P<0.01$ vs. control; $\#$ $P<0.01$ vs. FLA

revealed that cortical neurons were not affected by flagellin in the absence of microglia during the whole observation period (Fig. 5f, g). Likewise, in contrast to loxoribine, LPS did not affect neuronal survival in cultures of purified neurons, as expected (Fig. 5f).

In summary, these findings demonstrate that activation of TLR5 in microglia results in neuronal apoptosis.

\section{Intrathecal flagellin induces neuronal injury in the cerebral cortex}

To evaluate the functional role of flagellin as TLR5 activator in the CNS in vivo, we injected mice intrathecally with flagellin or PBS serving as control. Immunohistochemical analysis of the cerebral cortex $72 \mathrm{~h}$ after injection revealed that flagellin induced significant neuronal loss of $32.3 \%$ compared to control as revealed by combined NeuN and DAPI labeling (Fig. 6a, b). Induction of apoptosis in the cerebral cortex was confirmed by immunostaining of active caspase 3-positive cells, which were increased by $58.0 \%$ in flagellin-injected animals compared to control (Fig. 6c). Furthermore, intrathecal application of flagellin led to increased microglial numbers $(52.3 \%)$ in the cerebral cortex compared to control condition (Fig. 6d, e).

\footnotetext{
(See figure on next page.)

Fig. 5 Flagellin induces neuronal cell death through TLR5 in vitro. a Co-cultures of C57BL/6 (WT) neurons and WT or T/r5 $5^{-1-}$ microglia were incubated with $100 \mathrm{ng} / \mathrm{ml}$ flagellin (FLA) for 72 h. Subsequently, cells were stained with NeuN antibody to mark neurons, and DAPI to label nuclei, and representative images are shown (scale bar, $50 \mu \mathrm{m} ; n=3$ ). b, c NeuN-positive cells in co-cultures treated with different FLA doses, as indicated, for $72 \mathrm{~h}$ (b), or with $100 \mathrm{ng} / \mathrm{ml}$ FLA for different time periods, as indicated (c), were quantified, and results were expressed as relative neuronal viability by setting the viability of control cells to $100 \% .1 \mu \mathrm{g} / \mathrm{ml}$ LPS served as positive control, whereas unstimulated condition served as negative control $(n=3)$. $\mathbf{d}$ Images of TUNEL-positive and DAPI-labeled nuclei in unstimulated (control) and FLA-treated co-cultures containing WT microglia are shown (scale bar, $50 \mu \mathrm{m} ; n=4$ ). e Quantification of TUNEL-positive cells in co-cultures incubated with different FLA doses, as indicated, and with LPS, serving as positive control, relative to control $(n=4)$. Data are expressed as mean \pm SEM. Results were analyzed by Kruskal-Wallis test followed by Dunn's post hoc test. ${ }^{*} P<0.05 ;{ }^{*} P<0.01$ vs. control; ${ }^{\#} P<0.01 \mathrm{vs.} T / 15^{-/-}$.f, $\mathbf{g}$ Purified neurons from C57BL/6 mice were incubated with various FLA doses, as indicated, 1 gg/ml LPS, or $1 \mathrm{mM}$ loxoribine (LOX) for $72 \mathrm{~h}$ (f), or were incubated with $100 \mathrm{ng} / \mathrm{ml}$ FLA for indicated durations (g, $n=3$ ). Subsequently, cells were stained with NeuN antibody and DAPI. NeuN-positive cells were quantified, and results were expressed as relative neuronal viability by setting the viability of control cells to $100 \%$. Data are expressed as mean \pm SEM. Results were analyzed by Kruskal-Wallis test followed by Dunn's post hoc test. ${ }^{*} P<0.05$ vs. control; n.s., not significant
} 

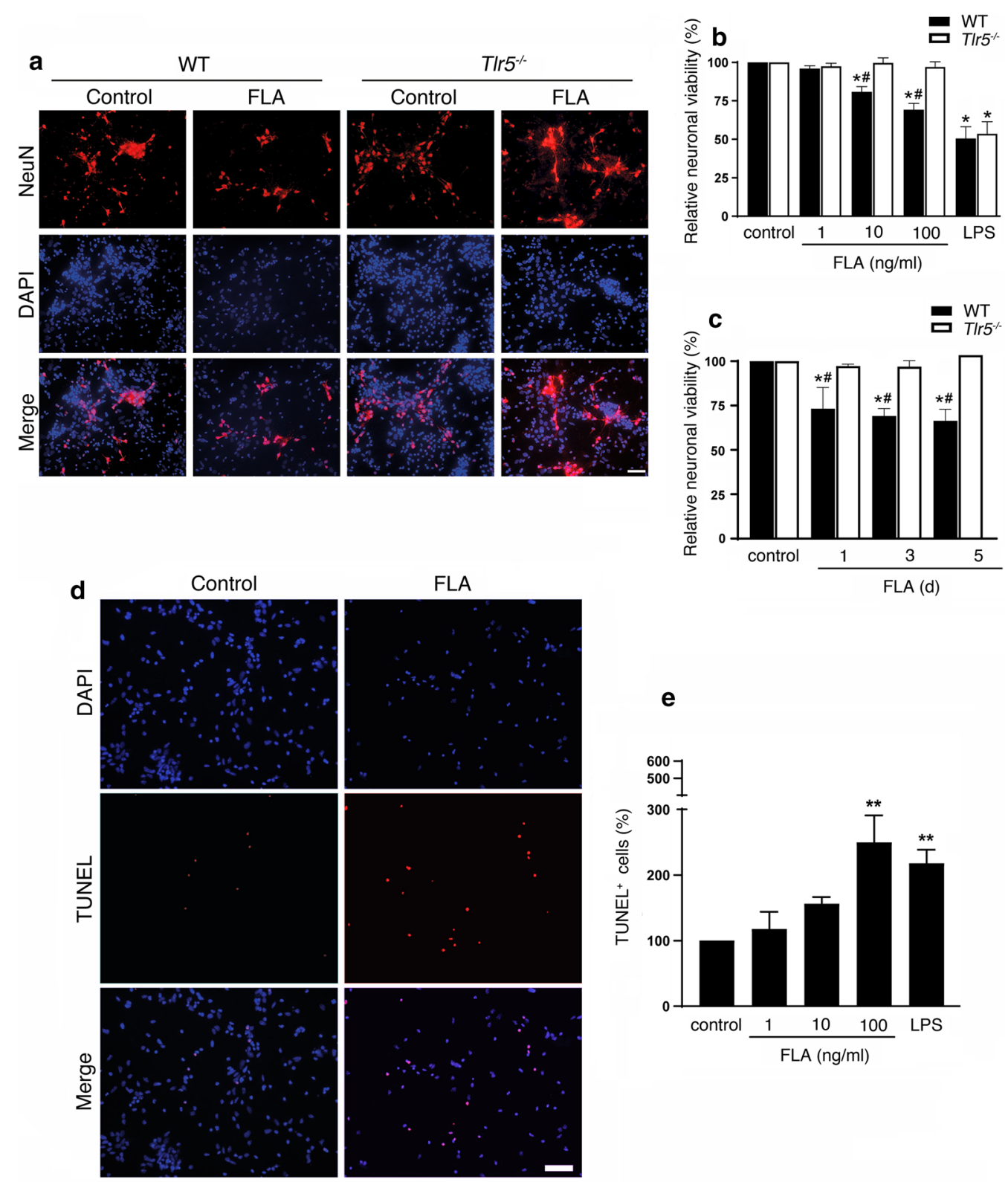

FLA
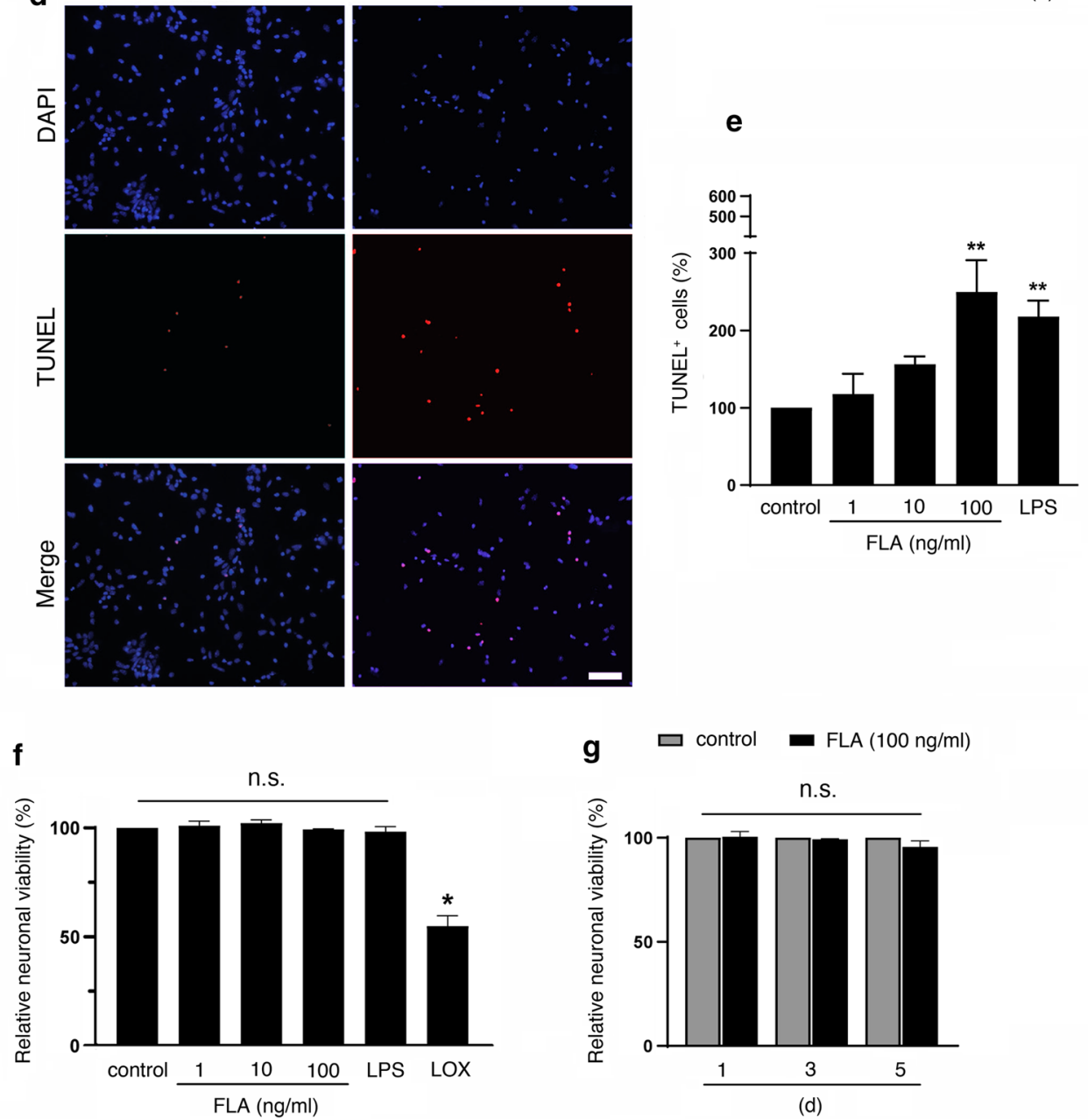

g 口 control $\square$ FLA (100 ng/ml)

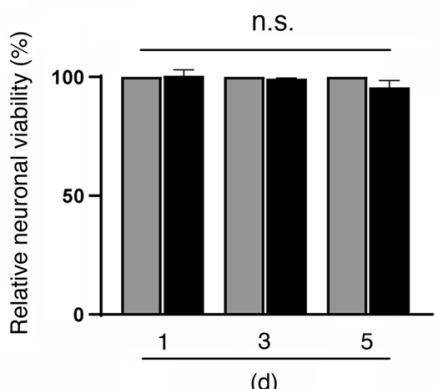



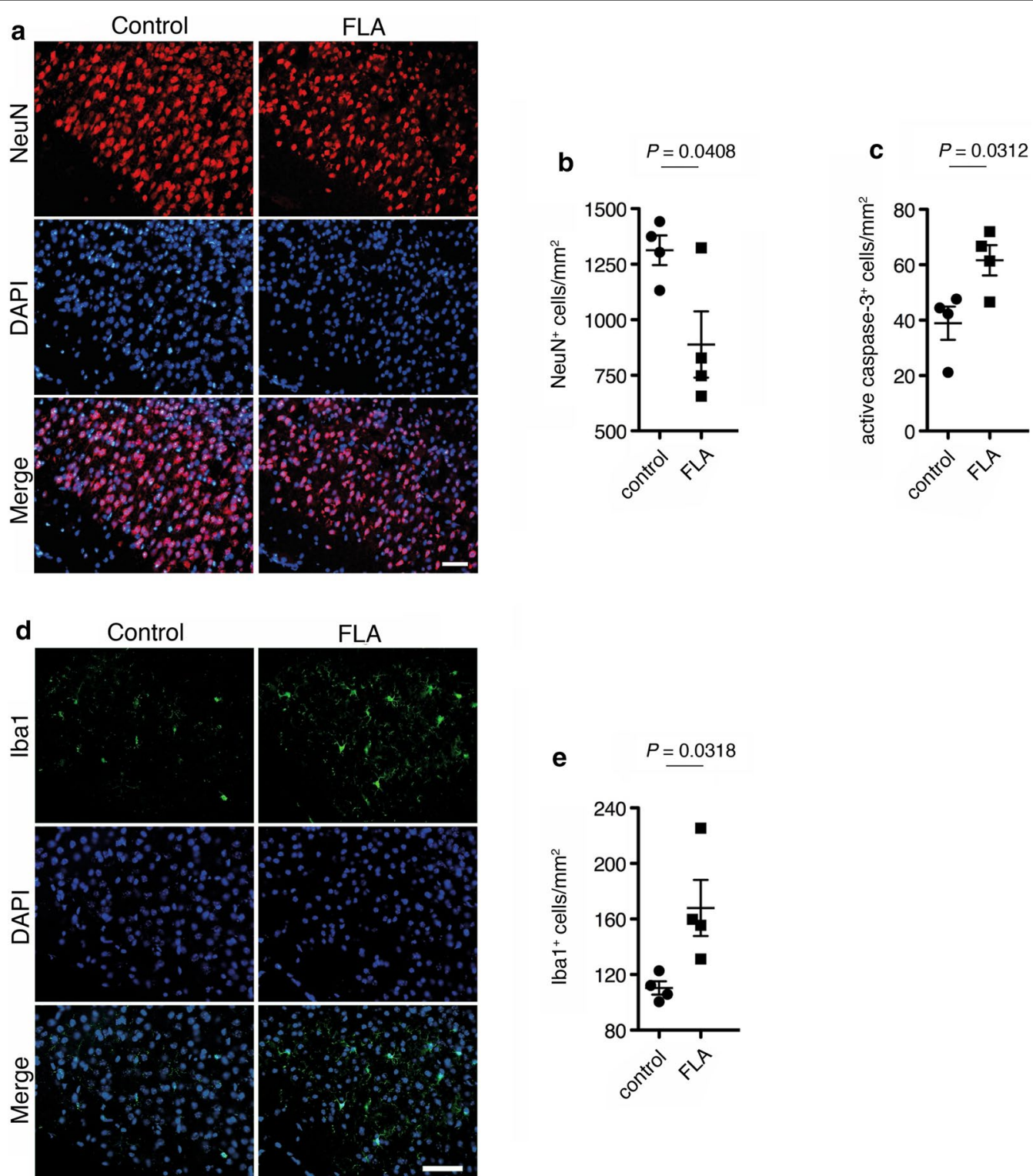

Fig. 6 Intrathecal flagellin triggers neuronal injury in the cerebral cortex. $1 \mu \mathrm{g}$ of flagellin (FLA) was injected intrathecally into C57BL/6 mice ( $n=4)$, while PBS served as control $(n=4)$. a After 3 d, brain sections were stained with NeuN antibody and DAPI, and representative images are shown (scale bar, $50 \mu \mathrm{m}$ ). b The density of NeuN-positive cells in the cerebral cortex was assessed. c Sections were stained with active caspase-3 antibody (images are not shown), and caspase-3-positive cells in the cerebral cortex were quantified. $\mathbf{d}$ Sections were immunostained with Ibal antibody and DAPI, and e Ibal-positive cells in the cerebral cortex were quantified. Results are presented as mean \pm SEM. Data were analyzed by Student's $t$-test and provided indicated $P$ values

Taken together, the TLR5 activator flagellin induces neuronal injury in the cerebral cortex in vivo.

\section{Discussion}

Microglia express all TLRs identified so far, and TLR signaling can have a profound impact on microglial function. TLR4 activation by its established ligand LPS, for example, triggers cytokine release from microglia and affects their proliferation [40,60, 65]. TLR1/2 signaling in microglia promotes a pro-tumorigenic phenotype of these cells [18], whereas TLR2 and TLR7 modulate microglial chemotaxis and cytokine release [29]. Moreover, activation of microglial TLR2, TLR4, and TLR7 contribute to neuronal injury [40,41]. Although TLR5 expression in human and mouse microglia was previously described $[4,52]$, and a few studies recently 
reported on a functional relevance for this receptor in the setting of various CNS disorders including neuropathic pain, stroke, and Alzheimer's disease (AD) [7, 24, 33, 64], its mode of action and functional consequences of this receptor activation in the brain has not been explored. While for most of the TLRs several agonists derived from pathogens and host-derived tissue were identified [61], the bacterial protein flagellin is the only established natural ligand for TLR5. Yet conversely, flagellin seems to activate further receptor systems, as flagellin from Legionella pneumophila triggers the release of proinflammatory molecules such as IL- $1 \beta$ from microglia, through the inflammasome Naip5-NLRC4 complex [32]. However, flagellin from Salmonella typhimurium as used in our current study did not result in IL- $1 \beta$ secretion from microglia, suggesting a pathogen-specific activation of TLR5 and subsequent phenotype induction in these cells.

TLR signaling plays a major role in initiating host defense responses in CNS microbial infection. While several TLRs including TLR4, which recognizes Gramnegative bacteria, TLR2, which detects lipoproteins from Gram-positive bacteria, and TLR9 as a sensor for bacterial and viral DNA, were extensively studied in CNS infection [20], data on TLR5 function in this context are rare. Among other TLRs, TLR5 in primate microglia, and also astrocytes, triggers the production of proinflammatory molecules in response to Borrelia burgdorferi, thereby possibly contributing to Lyme neuroborreliosis [3]. Furthermore, TLR5 senses flagellin from Listeria monocytogenes [22], which represents one of the major pathogens causing bacterial meningitis in humans. In our study, we demonstrate that exposure to flagellin modulates diverse functions of mouse microglia as the brain's primary immune cells. First, it triggers the release of specific inflammatory molecules, second, it modulates chemotaxis, third, it increases phagocytosis, and finally, it triggers neuronal apoptosis through microglial activation. All these effects require functional TLR5 signaling, as demonstrated in experiments using $T l r 5^{-1-}$ microglia and/or TLR5-neutralizing antibody. Moreover, our study provides evidence that activation of TLR5 in microglia triggers the PI3K/Akt/mTORC1 pathway, which is required for the different microglial functions described above. Our findings in microglia are in line with studies on peripheral macrophages, in which flagellin triggers the release of TNF- $\alpha$ through PI3K/Akt/ mTORC1 signaling [2]. However, the downstream signaling cascade induced by activation of distinct TLRs in microglia seems to involve different molecular components, as PI3K and Rac inhibition impairs both TLR2and TLR7-mediated microglial migration, whereas Akt phosphorylation is required only for TLR2-, but not for TLR7-induced migration [29]. In peripheral immune cells, the intracellular TLR adapter MyD88 represents a common link for TLR2, TLR5, and TLR7 signaling [35]. Although not investigated in our study, this adapter is likely required in microglial TLR5 signaling as well, as it is crucial for microglial TLR2 and TLR7 signaling $[36,41]$. Interestingly, the release of MIP-2 from microglia exposed to LPS was significantly enhanced in the absence of TLR5, while IL-6 and IL-10 responses were reduced compared to wild-type cells. One may speculate that TLR5 cooperates with TLR4 [28], which is the LPS-recognizing receptor, in an unknown manner, resulting in enhancing (IL-6, IL-10) or inhibiting (MIP-2) effects on cytokine production. In addition, as TLR 5 can interact with TIR-domain-containing adapter-inducing interferon- $\beta$ (TRIF), LPS stimulation might modulate the cytokine response through the associated pathway [8]. Furthermore, while microglial production of the particular cytokines/chemokines in response to flagellin was clearly mediated by TLR 5 in our study, other receptors and downstream signaling pathways activated by flagellin, which trigger different cytokine responses and subsequently induce a specific microglial phenotype may exist. The observed reduction in the microglial release of cytokines at higher flagellin doses may be explained by the fact that the interaction between TLR 5 and flagellin is based on protein structure-mediated receptor-ligand binding at the ratio of 1:1. In addition, flagellin is capable of interacting with itself through the backbone protein [66]. Thus, at $100 \mathrm{ng} / \mathrm{ml}$ flagellin saturation of the receptor system in microglia might be achieved, and higher flagellin doses $(1000 \mathrm{ng} / \mathrm{ml})$ may form flagellin aggregates, which inhibit further linear activation. Finally, TLR5-mediated signaling in microglia may be negatively regulated at specific flagellin concentrations. In general, protein interactions within the TLR signaling pathway are targeted by one specific or several inhibitors [16], and fine-tuning of the TLR5 signaling pathway might be achieved not only through a cascade of regulators, but also by specific ligand concentrations.

Microglia are activated in essentially all CNS disorders, and the subsequent neuroinflammation, in its characteristic form common to various neurodegenerative diseases, is shaped by their migratory, phagocytic, and antigen-presenting properties. As discussed above, TLRs detect pathogen-associated components, but can also be activated by host-derived factors. For instance, the extracellular matrix component versican activates TLR2, tenascin $\mathrm{C}$ and heat-shock protein 60 signal through TLR4, and sequence-specific microRNAs activate TLR7 $[5,17,27,36,41]$. Recognition of such endogenous molecules, potentially derived from injured host tissue, by TLRs and the subsequent inflammatory response may have important pathological implications, as both 
processes contribute to various CNS injury models, including mouse models for various neurodegenerative diseases [41, 53]. Notably, TLR5 specifically recognizes flagellin from bacteria, and bacterial infection has been associated with the increased occurrence of neurodegenerative diseases, such as $\mathrm{AD}[26,44,49]$. While in the healthy state, TLR5 expression in mouse and human brain is only weak [21, 42], expression of TLR5 mRNA in the $\mathrm{AD}$ cortex is increased and correlates with the expression of the constitutive microglial cell marker Iba1 $[7,24]$. Matching our findings in mouse microglia, human THP-1 monocytes exposed to flagellin release cytokines including TNF- $\alpha$, and this release is prevented by TLR 5 inhibition [24]. Consistent reports of increased TLR5 expression exist in the context of further neurodegenerative disorders, such as Parkinson's disease and dementia with Lewy bodies [14, 43]. We report herein that TLR5 is abundantly expressed in adult microglia whose activation represents a major hallmark in neurodegenerative diseases, and that signaling through this receptor contributes to neuronal apoptosis. Taking into account that TLR 5 activation seems to be involved in the different pathological states outlined above, it is conceivable that endogenous, yet unidentified ligands for TLR5 exist. In accordance with this, contribution of TLR5 to further CNS pathologies was recently reported. In neuropathic pain, TLR5 function is involved in mechanical allodynia [64], while in stroked mice, TLR5 activation induces NF- $\mathrm{kB}$ via Akt phosphorylation [33], matching our data on flagellin-increased Akt phosphorylation in microglia. Besides injecting mice intrathecally with flagellin as a proof-of-concept demonstration for a role of activated TLR5 in neuronal injury, we herein tested the impact of TLR 5 signaling in the setting of glioblastoma, the most aggressive brain tumor in adults. The experiments using the GL261 glioma mouse model were prompted by our previous results on the promotion of tumor growth involving TLR2, TLR4, and TLR7 signaling $[5,12,27]$, and were driven by the assumption that TLR5 might detect host-derived molecules. In line with this, high mobility group box 1 was recently suggested to bind to TLR5, thereby activating proinflammatory signaling with the functional consequence of pain [10]. In our experimental glioma set-up, however, neither TLR5 stimulation by flagellin nor deletion of TLR 5 signaling as assessed by analyzing $T l r 5^{-/}$mice, had an impact on glioma growth. Therefore, TLRs do not seem to be uniformly involved in the regulation of glioma growth.

\section{Conclusions}

Our study establishes TLR5 and its ligand flagellin as modulators of microglial function and neuronal apoptosis. Further research will be required to investigate the probably more complex role of TLR5 in the CNS and to establish clinical consequences of CNS injury triggered by this receptor in distinct CNS disorders, such as bacterial infection and neurodegenerative diseases. Finally, TLR5 signaling and subsequent regulation of microglial function may be important not only for pathological but also for physiological processes in the CNS.

\section{Supplementary information}

Supplementary information accompanies this paper at https://doi. org/10.1186/s40478-020-01031-3.

Additional file 1: Primary cultures of microglia, astrocytes, and neurons. Microglia, astrocytes, and neurons were isolated from C57BL/6 mice as described in the Methods section. Phase contrast images display the respective cell type, as indicated, after $3 \mathrm{~d}$ in vitro. Scale bar, $10 \mu \mathrm{m}$.

Additional file 2: Protein concentrations of cytokines/chemokines released from wild-type and $T / r 5^{-1-}$ microglia. Multiplex immunoassay was used to detect cytokines/chemokines, as indicated, in supernatants of cultured neonatal microglia from C57BL/6 (wild-type, WT) and T/r5 mice in response to $100 \mathrm{ng} / \mathrm{ml}$ flagellin (FLA) after $24 \mathrm{~h}$. Unstimulated cells served as negative control, while LPS (100 ng/ml) was used as positive control $(n=3)$. Data are expressed in $\mathrm{pg} / \mathrm{ml} \pm$ SD. n.d., not detectable.

Additional file 3: Flagellin does not induce microglial injury or cell loss. C57BL/6 microglia were incubated with different flagellin (FLA) doses, as indicated, for $72 \mathrm{~h}$. Unstimulated cells served as negative control. Subsequently, cells were stained with IB4 to mark microglia, TUNEL assay to mark apoptotic cells, and DAPI. (a) Representative image of microglia exposed to $5 \mu \mathrm{g} / \mathrm{ml}$ FLA. Scale bar, $50 \mu \mathrm{m}$. (b) IB4- and (c) TUNEL-positive cells were quantified. Results were expressed as absolute number of IB4-positive or TUNEL-positive cells per field (c). Data are expressed as mean \pm SEM. Results were analyzed by Kruskal-Wallis test followed by Dunn's post hoc test. n.S., not significant.

Additional file 4: Neither TLR5 deficiency nor exposure to flagellin does affect glioma growth ex vivo. (a) mCherry GL261 glioma cells were inoculated into organotypic brain slices (OBS) derived from P14-P16 C57BL/6 ( $n=2$; number of inoculated tumors: 27$)$ and P14-P16 TIr $5^{-1-}$ mice $(n=3$; number of inoculated tumors: 21) and cultured for $4 \mathrm{~d}$. Subsequently, OBS were fixed, stained with Hoechst, and scanned by confocal microscopy, followed by 3D surface reconstruction of gliomas and measurement of tumor volumes. (b) OBS derived from P14-P16 C57BL/6 mice were inoculated with mCherry glioma GL261 cells and stimulated with FLA (100 ng/ $\mathrm{ml}, n=3$; number of analyzed tumors: 12). Tumor volume was compared to unstimulated control ( $n=2$; number of analyzed tumors: 16$)$. Results are represented as mean \pm SEM. Data were analyzed by Student's $t$-test. n.s., not significant.

\section{Abbreviations}

A $\beta$ : beta-amyloid; AD: Alzheimer's disease; Akt: serine/threonine protein kinase B; CNS: central nervous system; DMSO: dimethyl sulfoxide; FLA: flagellin; IL: interleukin; LPS: lipopolysaccharide; $\mathrm{mTORC1:} \mathrm{mammalian} \mathrm{target} \mathrm{of} \mathrm{rapamycin}$ complex 1; NeuN: neuronal nuclei; NF-kB: nuclear factor 'kappa-light-chainenhancer' of activated B-cells; NO: nitric oxide; PDK1: 3-phosphoinositidedependent kinase-1; PI3K: phosphoinositide 3-kinase; Rac: rho family of GTPases; TLR: Toll-like receptor; TUNEL: TdT-mediated dUTP-biotin nick end labeling.

\section{Acknowledgements}

We thank Prof. Tohru Yoshioka (Waseda University, Japan) for reading the manuscript and useful comments. We also thank Regina Piske, Nadine Scharek, and Maren Wendt for excellent technical assistance, and the Kettenmann and Lehnardt laboratories for helpful discussion. Lukas Hinkelmann received a Student scholarship from the Charité-Universitätsmedizin Berlin. Victor Kumbol received a PhD fellowship from the Einstein Center for Neurosciences Berlin. 


\section{Authors' contributions}

H.K., S.L., and M.N. conceived the study and wrote the manuscript. M.F. and P.J. planned the experiments. M.I., L.H., L.D.K., I.E.E., V.K., A.B., and C.K. planned and carried out the experiments. All authors read and approved the final manuscript.

\section{Funding}

Open access funding provided by Projekt DEAL. This work was supported by NeuroCure Exc 257 (to H.K. and S.L.), Deutsche Forschungsgemeinschaft (DFG; LE 2420/2-1, SFB-TRR167/B03, to S.L.), Helmholtz-Gemeinschaft, Zukunftsthema "Immunology and Inflammation" (ZT-0027, to H.K.), the German Federal Ministry of Education and Research (BMBF) within the consortium InfectControl 2020 (Project NeoBiom, grant ID 03ZZ0829C), the national platform for zoonosis research (Project NAMPatIn, grant ID 01KI1906) (to M.F.), and Japan Society of the Promotion of Science (JSPS) Postdoctoral Fellowships for Research Abroad (to M.I.).

\section{Availability of data and materials}

The datasets used and/or analyzed during the current study are available from the corresponding authors on reasonable request.

\section{Ethics approval and consent to participate}

Animals were maintained and handled in accordance with the German Animal Protection Law and approved by the Regional Office for Health and Social Services in Berlin (Landesamt für Gesundheit und Soziales - LAGeSo, Berlin, Germany).

\section{Consent for publication}

Not applicable

\section{Competing interests}

The authors declare that they have no competing interests.

\section{Author details}

${ }^{1}$ Cellular Neuroscience, Max-Delbrück-Center for Molecular Medicine in the Helmholtz Association, Berlin, Germany. ${ }^{2}$ Institute of Cell Biology and Neurobiology, Charité - Universitätsmedizin Berlin, corporate member of Freie Universität Berlin, Humboldt-Universität zuBerlin, and Berlin Institute of Health, Berlin, Germany. ${ }^{3}$ Charité - Universitätsmedizin Berlin, corporate member of Freie Universität Berlin, Humboldt-Universität zu Berlin, and Berlin Institute of Health, Berlin, Germany. ${ }^{4}$ Institute of Microbiology and Epizootics, Centre for Infection Medicine, Freie Universität Berlin, Berlin, Germany. ${ }^{5}$ Laboratory of Pathophysiology, Graduate School of Pharmaceutical Sciences, Kyushu University, Fukuoka, Japan. ${ }^{6}$ Department of Neurology, Charité Universitätsmedizin Berlin, corporate member of Freie Universität Berlin, Humboldt-Universität zu Berlin, and Berlin Institute of Health, Berlin, Germany. ${ }^{7}$ Present Address: Pharmaceutical Research Division, Takeda Pharmaceutical Company Limited, Fujisawa, Japan.

Received: 8 July 2020 Accepted: 29 August 2020 Published online: 10 September 2020

\section{References}

1. Al-Obaidi MMJ, Desa MNM (2018) Mechanisms of blood brain barrier disruption by different types of bacteria, and bacterial-host interactions facilitate the bacterial pathogen invading the brain. Cell Mol Neurobiol 38:1349-1368. https://doi.org/10.1007/s10571-018-0609-2

2. Bao W, Wang Y, Fu Y, Jia X, Li J, Vangan N, Bao L, Hao H, Wang Z (2015) mTORC1 regulates flagellin-induced inflammatory response in macrophages. PLoS ONE 10:e0125910. https://doi.org/10.1371/journ al.pone.0125910

3. Bernardino AL, Myers TA, Alvarez X, Hasegawa A, Philipp MT (2008) Toll-like receptors: insights into their possible role in the pathogenesis of lyme neuroborreliosis. Infect Immun 76:4385-4395. https://doi. org/10.1128/IAI.00394-08

4. Bsibsi M, Ravid R, Gveric D, van Noort JM (2002) Broad expression of Toll-like receptors in the human central nervous system. J Neuropathol Exp Neurol 61:1013-1021
5. Buonfiglioli A, Efe IE, Guneykaya D, Ivanov A, Huang Y, Orlowski E, Kruger C, Deisz RA, Markovic D, Fluh C et al (2019) let-7 microRNAs regulate microglial function and suppress glioma growth through Toll-Like Receptor 7. Cell Rep 29(3460-3471):e3467. https://doi.org/10.1016/j. celrep.2019.11.029

6. Cameron JS, Alexopoulou L, Sloane JA, DiBernardo AB, Ma Y, Kosaras B, Flavell R, Strittmatter SM, Volpe J, Sidman R et al (2007) Toll-like receptor 3 is a potent negative regulator of axonal growth in mammals. J Neurosci 27:13033-13041

7. Chakrabarty P, Li A, Ladd TB, Strickland MR, Koller EJ, Burgess JD, Funk CC, Cruz PE, Allen M, Yaroshenko M et al (2018) TLR5 decoy receptor as a novel anti-amyloid therapeutic for Alzheimer's disease. J Exp Med 215:2247-2264. https://doi.org/10.1084/jem.20180484

8. Choi YJ, Im E, Pothoulakis C, Rhee SH (2010) TRIF modulates TLR5dependent responses by inducing proteolytic degradation of TLR5. J Biol Chem 285:21382-21390. https://doi.org/10.1074/jbc.M110.115022

9. Coureuil M, Lecuyer H, Bourdoulous S, Nassif X (2017) A journey into the brain: insight into how bacterial pathogens cross blood-brain barriers. Nat Rev Microbiol 15:149-159. https://doi.org/10.1038/nrmicro.2016.178

10. Das N, Dewan V, Grace PM, Gunn RJ, Tamura R, Tzarum N, Watkins LR, Wilson IA, Yin H (2016) HMGB1 activates proinflammatory signaling via TLR5 leading to allodynia. Cell Rep 17:1128-1140. https://doi.org/10.1016/j. celrep.2016.09.076

11. Diers-Fenger M, Kirchhoff F, Kettenmann H, Levine JM, Trotter J (2001) AN2/NG2 protein-expressing glial progenitor cells in the murine CNS isolation, differentiation, and association with radial glia. Glia 34:213-228. https://doi.org/10.1002/glia.1055

12. Dzaye O, Hu F, Derkow K, Haage V, Euskirchen P, Harms C, Lehnardt S, Synowitz M, Wolf SA, Kettenmann H (2016) Glioma stem cells but not bulk glioma cells upregulate IL-6 secretion in microglia/brain macrophages via Toll-like receptor 4 signaling. J Neuropathol Exp Neurol 75:429-440. https ://doi.org/10.1093/jnen/nlw016

13. Eaves-Pyles T, Murthy K, Liaudet L, Virag L, Ross G, Soriano FG, Szabo C, Salzman AL (2001) Flagellin, a novel mediator of Salmonella-induced epithelial activation and systemic inflammation: I kappa B alpha degradation, induction of nitric oxide synthase, induction of proinflammatory mediators, and cardiovascular dysfunction. J Immunol 166:1248-1260. https://doi.org/10.4049/jimmunol.166.2.1248

14. Frank S, Copanaki E, Burbach GJ, Muller UC, Deller T (2009) Differential regulation of toll-like receptor mRNAs in amyloid plaque-associated brain tissue of aged APP23 transgenic mice. Neurosci Lett 453:41-44. https:// doi.org/10.1016/j.neulet.2009.01.075

15. Gewirtz AT, Navas TA, Lyons S, Godowski PJ, Madara JL (2001) Cutting edge: bacterial flagellin activates basolaterally expressed TLR5 to induce epithelial proinflammatory gene expression. J Immunol 167:1882-1885. https://doi.org/10.4049/jimmunol.167.4.1882

16. Guven-Maiorov E, Keskin O, Gursoy A, Nussinov R (2015) A structural view of negative regulation of the Toll-like receptor-mediated inflammatory pathway. Biophys J 109:1214-1226. https://doi.org/10.1016/j. bpj.2015.06.048

17. Haage V, Semtner M, Vidal RO, Hernandez DP, Pong WW, Chen Z, Hambardzumyan D, Magrini V, Ly A, Walker J et al (2019) Comprehensive gene expression meta-analysis identifies signature genes that distinguish microglia from peripheral monocytes/macrophages in health and glioma. Acta Neuropathol Commun 7:20. https://doi.org/10.1186/s4047 8-019-0665-y

18. Hambardzumyan D, Gutmann DH, Kettenmann H (2016) The role of microglia and macrophages in glioma maintenance and progression. Nat Neurosci 19:20-27. https://doi.org/10.1038/nn.4185

19. Hanel RA, Araujo JC, Antoniuk A, da Silva Ditzel LF, Flenik Martins LT, Linhares MN (2000) Multiple brain abscesses caused by Salmonella typhi: case report. Surg Neurol 53:86-90. https://doi.org/10.1016/s0090 $-3019(99) 00161-5$

20. Hanke ML, Kielian T (2011) Toll-like receptors in health and disease in the brain: mechanisms and therapeutic potential. Clin Sci (Lond) 121:367387. https://doi.org/10.1042/CS20110164

21. Hawrylycz MJ, Lein ES, Guillozet-Bongaarts AL, Shen EH, Ng L, Miller JA, van de Lagemaat LN, Smith KA, Ebbert A, Riley ZL et al (2012) An anatomically comprehensive atlas of the adult human brain transcriptome. Nature 489:391-399. https://doi.org/10.1038/nature11405 
22. Hayashi F, Smith KD, Ozinsky A, Hawn TR, Yi EC, Goodlett DR, Eng JK, Akira $\mathrm{S}$, Underhill DM, Aderem A (2001) The innate immune response to bacterial flagellin is mediated by Toll-like receptor 5. Nature 410:1099-1103. https://doi.org/10.1038/35074106

23. Heneka MT, Carson MJ, El Khoury J, Landreth GE, Brosseron F, Feinstein DL, Jacobs AH, Wyss-Coray T, Vitorica J, Ransohoff RM et al (2015) Neuroinflammation in Alzheimer's disease. Lancet Neurol 14:388-405. https:// doi.org/10.1016/S1474-4422(15)70016-5

24. Herrera-Rivero M, Santarelli F, Brosseron F, Kummer MP, Heneka MT (2019) Dysregulation of TLR5 and TAM Ligands in the Alzheimer's Brain as Contributors to Disease Progression. Mol Neurobiol 56:6539-6550. https ://doi.org/10.1007/s12035-019-1540-3

25. Hoffmann O, Braun JS, Becker D, Halle A, Freyer D, Dagand E, Lehnardt S, Weber JR (2007) TLR2 mediates neuroinflammation and neuronal damage. J Immunol 178:6476-6481

26. Honjo K, van Reekum R, Verhoeff NP (2009) Alzheimer's disease and infection: do infectious agents contribute to progression of Alzheimer's disease? Alzheimers Dement 5:348-360. https://doi.org/10.1016/j. jalz.2008.12.001

27. Hu F, Dzaye O, Hahn A, Yu Y, Scavetta RJ, Dittmar G, Kaczmarek AK, Dunning KR, Ricciardelli C, Rinnenthal JL et al (2015) Glioma-derived versican promotes tumor expansion via glioma-associated microglial/macrophages Toll-like receptor 2 signaling. Neuro Oncol 17:200-210. https:// doi.org/10.1093/neuonc/nou324

28. Hussain S, Johnson CG, Sciurba J, Meng X, Stober VP, Liu C, Cyphert-Daly JM, Bulek K, Qian W, Solis A et al (2020) TLR5 participates in the TLR4 receptor complex and promotes MyD88-dependent signaling in environmental lung injury. Elife. https://doi.org/10.7554/eLife.50458

29. Ifuku M, Buonfiglioli A, Jordan P, Lehnardt S, Kettenmann H (2016) TLR2 controls random motility, while TLR7 regulates chemotaxis of microglial cells via distinct pathways. Brain Behav Immun 58:338-347. https://doi. org/10.1016/j.bbi.2016.08.003

30. Iliev Al, Stringaris AK, Nau R, Neumann H (2004) Neuronal injury mediated via stimulation of microglial toll-like receptor-9 (TLR9). Faseb J 18:412-414

31. Iqbal M, Philbin VJ, Withanage GS, Wigley P, Beal RK, Goodchild MJ, Barrow P, McConnell I, Maskell DJ, Young J et al (2005) Identification and functional characterization of chicken toll-like receptor 5 reveals a fundamental role in the biology of infection with Salmonella enterica serovar typhimurium. Infect Immun 73:2344-2350. https://doi.org/10.1128/ IAl.73.4.2344-2350.2005

32. Jamilloux $Y$, Pierini $R$, Querenet $M$, Juruj $C$, Fauchais $A L$, Jauberteau $M O$, Jarraud S, Lina G, Etienne J, Roy CR et al (2013) Inflammasome activation restricts Legionella pneumophila replication in primary microglial cells through flagellin detection. Glia 61:539-549. https://doi.org/10.1002/ glia.22454

33. Jeong J, Kim S, Lim DS, Kim SH, Doh H, Kim SD, Song YS (2017) TLR5 Activation through NF-kappaB is a neuroprotective mechanism of postconditioning after cerebral ischemia in mice. Exp Neurobiol 26:213-226. https://doi.org/10.5607/en.2017.26.4.213

34. Karim M, Islam N (2002) Salmonella meningitis: report of three cases in adults and literature review. Infection 30:104-108. https://doi. org/10.1007/s15010-002-2071-8

35. Kawai T, Akira S (2010) The role of pattern-recognition receptors in innate immunity: update on Toll-like receptors. Nat Immunol 11:373-384. https ://doi.org/10.1038/ni.1863

36. Lehmann SM, Kruger C, Park B, Derkow K, Rosenberger K, Baumgart J, Trimbuch T, Eom G, Hinz M, Kaul Det al (2012) An unconventional role for miRNA: let-7 activates Toll-like receptor 7 and causes neurodegeneration. Nat Neurosci 15:827-835. Doi nn.3113 [pii]https://doi.org/10.1038/ nn. 3113

37. Lehnardt S (2010) Innate immunity and neuroinflammation in the CNS: the role of microglia in Toll-like receptor-mediated neuronal injury. Glia 58:253-263. https://doi.org/10.1002/glia.20928

38. Lehnardt S, Henneke P, Lien E, Kasper DL, Volpe JJ, Bechmann I, Nitsch R, Weber JR, Golenbock DT, Vartanian T (2006) A mechanism for neurodegeneration induced by group B streptococci through activation of the TLR2/MyD88 pathway in microglia. J Immunol 177:583-592

39. Lehnardt S, Lachance C, Patrizi S, Lefebvre S, Follett PL, Jensen FE, Rosenberg PA, Volpe JJ, Vartanian T (2002) The toll-like receptor TLR4 is necessary for lipopolysaccharide-induced oligodendrocyte injury in the CNS. J Neurosci 22:2478-2486

40. Lehnardt S, Massillon L, Follett P, Jensen FE, Ratan R, Rosenberg PA, Volpe $\mathrm{JJ}$, Vartanian T (2003) Activation of innate immunity in the CNS triggers neurodegeneration through a Toll-like receptor 4-dependent pathway. Proc Natl Acad Sci U S A 100:8514-8519

41. Lehnardt S, Schott E, Trimbuch T, Laubisch D, Krueger C, Wulczyn G, Nitsch R, Weber JR (2008) A vicious cycle involving release of heat shock protein 60 from injured cells and activation of toll-like receptor 4 mediates neurodegeneration in the CNS. J Neurosci 28:2320-2331

42. Lein ES, Hawrylycz MJ, Ao N, Ayres M, Bensinger A, Bernard A, Boe AF, Boguski MS, Brockway KS, Byrnes EJ et al (2007) Genome-wide atlas of gene expression in the adult mouse brain. Nature 445:168-176. https:// doi.org/10.1038/nature05453

43. Letiembre M, Liu Y, Walter S, Hao W, Pfander T, Wrede A, Schulz-Schaeffer W, Fassbender K (2009) Screening of innate immune receptors in neurodegenerative diseases: a similar pattern. Neurobiol Aging 30:759-768. https://doi.org/10.1016/j.neurobiolaging.2007.08.018

44. Maheshwari P, Eslick GD (2015) Bacterial infection and Alzheimer's disease: a meta-analysis. J Alzheimers Dis 43:957-966. https://doi. org/10.3233/JAD-140621

45. Markovic DS, Glass R, Synowitz M, Rooijen N, Kettenmann H (2005) Microglia stimulate the invasiveness of glioma cells by increasing the activity of metalloprotease-2. J Neuropathol Exp Neurol 64:754-762

46. Mattei D, Ivanov A, Ferrai C, Jordan P, Guneykaya D, Buonfiglioli A, Schaafsma W, Przanowski P, Deuther-Conrad W, Brust D, Hesse S, Patt M, Sabri O, Ross TL, Eggen BJL, Boddeke EWGM, Kaminska B, Beule D, Pombo A, Kettenmann H, Wolf SA (2017) Maternal immune activation results in complex microglial transcriptome signature in the adult offspring that is reversed by minocycline treatment. Transl Psychiatry 7:e1120. https://doi. org/10.1038/tp.2017.80

47. McDermott PF, Ciacci-Woolwine F, Snipes JA, Mizel SB (2000) High-affinity interaction between gram-negative flagellin and a cell surface polypeptide results in human monocyte activation. Infect Immun 68:5525-5529. https://doi.org/10.1128/iai.68.10.5525-5529.2000

48. Means TK, Hayashi F, Smith KD, Aderem A, Luster AD (2003) The Toll-like receptor 5 stimulus bacterial flagellin induces maturation and chemokine production in human dendritic cells. J Immunol 170:5165-5175. https:// doi.org/10.4049/jimmunol.170.10.5165

49. Miklossy J (2011) Alzheimer's disease - a neurospirochetosis. Analysis of the evidence following Koch's and Hill's criteria. J Neuroinflammation 8:90. https://doi.org/10.1186/1742-2094-8-90

50. Minghetti L (2005) Role of inflammation in neurodegenerative diseases. Curr Opin Neurol 18:315-321. https://doi.org/10.1097/01.wco.00001 69752.54191 .97

51. Munukka E, Wiklund P, Partanen T, Valimaki S, Laakkonen EK, Lehti M, Fischer-Posovzsky P, Wabitsch M, Cheng S, Huovinen P et al (2016) Adipocytes as a link between gut microbiota-derived flagellin and hepatocyte fat accumulation. PLoS ONE 11:e0152786. https://doi.org/10.1371/journ al.pone. 0152786

52. Olson JK, Miller SD (2004) Microglia initiate central nervous system innate and adaptive immune responses through multiple TLRs. J Immunol 173:3916-3924

53. Owens T (2009) Toll-like receptors in neurodegeneration. Curr Top Microbiol Immunol 336:105-120. https://doi.org/10.1007/978-3-642-00549-7_6

54. Pannell M, Meier MA, Szulzewsky F, Matyash V, Endres M, Kronenberg G, Prinz V, Waiczies S, Wolf SA, Kettenmann H (2016) The subpopulation of microglia expressing functional muscarinic acetylcholine receptors expands in stroke and Alzheimer's disease. Brain Struct Funct 221:11571172. https://doi.org/10.1007/s00429-014-0962-y

55. Prinz M, Hanisch UK (1999) Murine microglial cells produce and respond to interleukin-18. J Neurochem 72:2215-2218. https://doi.org/10.104 6/j.1471-4159.1999.0722215.x

56. Rhee SH, Kim H, Moyer MP, Pothoulakis C (2006) Role of MyD88 in phosphatidylinositol 3-kinase activation by flagellin/toll-like receptor 5 engagement in colonic epithelial cells. J Biol Chem 281:18560-18568. https://doi.org/10.1074/jbc.M513861200

57. Rivest $S$ (2009) Regulation of innate immune responses in the brain. Nat Rev Immunol 9:429-439. https://doi.org/10.1038/nri2565

58. Sankowski R, Mader S, Valdes-Ferrer SI (2015) Systemic inflammation and the brain: novel roles of genetic, molecular, and environmental cues 
as drivers of neurodegeneration. Front Cell Neurosci 9:28. https://doi. org/10.3389/fncel.2015.00028

59. Stockhammer OW, Zakrzewska A, Hegedus Z, Spaink HP, Meijer AH (2009) Transcriptome profiling and functional analyses of the zebrafish embryonic innate immune response to Salmonella infection. J Immunol 182:5641-5653. https://doi.org/10.4049/jimmunol.0900082

60. Su Y, Zhang Z, Trautmann K, Xu S, Schluesener HJ (2005) TLR and NOD2 ligands induce cell proliferation in the rat intact spinal cord. J Neuropathol Exp Neurol 64:991-997. https://doi.org/10.1097/01.jnen.00001 87051.74265 .56

61. Takeuchi O, Akira S (2010) Pattern recognition receptors and inflammation. Cell 140:805-820. https://doi.org/10.1016/j.cell.2010.01.022

62. Uematsu S, Jang MH, Chevrier N, Guo Z, Kumagai Y, Yamamoto M, Kato H, Sougawa N, Matsui H, Kuwata H et al (2006) Detection of pathogenic intestinal bacteria by Toll-like receptor 5 on intestinal CD11c + lamina propria cells. Nat Immunol 7:868-874. https://doi.org/10.1038/ni1362

63. Wiggins H, Rappoport J (2010) An agarose spot assay for chemotactic invasion. Biotechniques 48:121-124. https://doi.org/10.2144/000113353

64. Xu ZZ, Kim YH, Bang S, Zhang Y, Berta T, Wang F, Oh SB, Ji RR (2015) Inhibition of mechanical allodynia in neuropathic pain by TLR5-mediated A-fiber blockade. Nat Med 21:1326-1331. https://doi.org/10.1038/ nm.3978
65. Yang X, Wang G, Cao T, Zhang L, Ma Y, Jiang S, Teng X, Sun X (2019) Large-conductance calcium-activated potassium channels mediate lipopolysaccharide-induced activation of murine microglia. J Biol Chem 294:12921-12932. https://doi.org/10.1074/jbc.RA118.006425

66. Yoon SI, Kurnasov O, Natarajan V, Hong M, Gudkov AV, Osterman AL, Wilson IA (2012) Structural basis of TLR5-flagellin recognition and signaling. Science 335:859-864. https://doi.org/10.1126/science.1215584

67. Yu Y, Nagai S, Wu H, Neish AS, Koyasu S, Gewirtz AT (2006) TLR5-mediated phosphoinositide 3-kinase activation negatively regulates flagellininduced proinflammatory gene expression. J Immunol 176:6194-6201. https://doi.org/10.4049/jimmunol.176.10.6194

\section{Publisher's Note}

Springer Nature remains neutral with regard to jurisdictional claims in published maps and institutional affiliations.
Ready to submit your research? Choose BMC and benefit from:

- fast, convenient online submission

- thorough peer review by experienced researchers in your field

- rapid publication on acceptance

- support for research data, including large and complex data types

- gold Open Access which fosters wider collaboration and increased citations

- maximum visibility for your research: over $100 \mathrm{M}$ website views per year

At BMC, research is always in progress.

Learn more biomedcentral.com/submissions 